\title{
Audit of the global carbon budget: estimate errors and their impact on uptake uncertainty
}

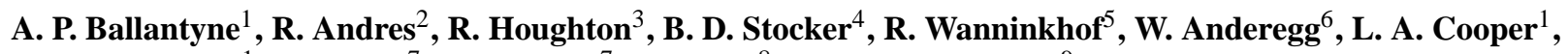 \\ M. DeGrandpre ${ }^{1}$, P. P. Tans ${ }^{7}$, J. B. Miller ${ }^{7}$, C. Alden ${ }^{8}$, and J. W. C. White ${ }^{9}$ \\ ${ }^{1}$ University of Montana, Missoula, MT, USA \\ ${ }^{2}$ Carbon Dioxide Information Analysis Center, Oak Ridge National Laboratory, Oak Ridge, TN, USA \\ ${ }^{3}$ Woods Hole Research Center, Falmouth, MA, USA \\ ${ }^{4}$ Imperial College, London, UK \\ ${ }^{5}$ Atlantic Oceanographic and Meteorological Laboratory of NOAA, Miami, FL, USA \\ ${ }^{6}$ Princeton Environmental Institute, Princeton University, Princeton, NJ, USA \\ ${ }^{7}$ Earth System Research Laboratory of NOAA, Boulder, CO, USA \\ ${ }^{8}$ Stanford University, Palo Alto, CA, USA \\ ${ }^{9}$ University of Colorado, Boulder, CO, USA
}

Correspondence to: A. P. Ballantyne (ashley.ballantyne@umontana.edu)

Received: 6 September 2014 - Published in Biogeosciences Discuss.: 22 October 2014

Revised: 14 March 2015 - Accepted: 19 March 2015 - Published: 30 April 2015

\begin{abstract}
Over the last 5 decades monitoring systems have been developed to detect changes in the accumulation of carbon $(\mathrm{C})$ in the atmosphere and ocean; however, our ability to detect changes in the behavior of the global $\mathrm{C}$ cycle is still hindered by measurement and estimate errors. Here we present a rigorous and flexible framework for assessing the temporal and spatial components of estimate errors and their impact on uncertainty in net $\mathrm{C}$ uptake by the biosphere. We present a novel approach for incorporating temporally correlated random error into the error structure of emission estimates. Based on this approach, we conclude that the $2 \sigma$ uncertainties of the atmospheric growth rate have decreased from 1.2 $\mathrm{Pg} \mathrm{Cyr}^{-1}$ in the $1960 \mathrm{~s}$ to $0.3 \mathrm{PgC} \mathrm{yr}^{-1}$ in the $2000 \mathrm{~s}$ due to an expansion of the atmospheric observation network. The $2 \sigma$ uncertainties in fossil fuel emissions have increased from $0.3 \mathrm{Pg} \mathrm{C} \mathrm{yr}^{-1}$ in the 1960 s to almost $1.0 \mathrm{Pg} \mathrm{C} \mathrm{yr}^{-1}$ during the 2000s due to differences in national reporting errors and differences in energy inventories. Lastly, while land use emissions have remained fairly constant, their errors still remain high and thus their global $\mathrm{C}$ uptake uncertainty is not trivial. Currently, the absolute errors in fossil fuel emissions rival the total emissions from land use, highlighting the extent to which fossil fuels dominate the global $\mathrm{C}$ budget. Because errors in the atmospheric growth rate have decreased
\end{abstract}

faster than errors in total emissions have increased, a 20\% reduction in the overall uncertainty of net $\mathrm{C}$ global uptake has occurred. Given all the major sources of error in the global $\mathrm{C}$ budget that we could identify, we are $93 \%$ confident that terrestrial $\mathrm{C}$ uptake has increased and $97 \%$ confident that ocean $\mathrm{C}$ uptake has increased over the last 5 decades. Thus, it is clear that arguably one of the most vital ecosystem services currently provided by the biosphere is the continued removal of approximately half of atmospheric $\mathrm{CO}_{2}$ emissions from the atmosphere, although there are certain environmental costs associated with this service, such as the acidification of ocean waters.

\section{Introduction: incorporating error into the global carbon budget}

Remarkable progress has been made in the study of the global carbon (C) budget over the last 50 years; however, errors associated with $\mathrm{CO}_{2}$ measurements and emission estimates still limit our confidence in calculating net $\mathrm{C}$ uptake from the atmosphere by the land and ocean. Since the first continuous measurements of atmospheric $\mathrm{CO}_{2}$ at Mauna Loa were started in 1959 (Keeling et al., 2011), the global net- 
work of continuous monitoring sites has expanded to over 300 sites and continues to grow (Global View-CO2, 2013). This expansion of the monitoring network allows us to resolve spatial patterns associated with the seasonal uptake and release of $\mathrm{CO}_{2}$ from and to the atmosphere on an unprecedented scale. Similarly, nearly 10 million measurements of the partial pressure of $\mathrm{CO}_{2}\left(p \mathrm{CO}_{2}\right)$ have been made in the world's oceans since 1957 (Bakker et al., 2014; Takahashi et al., 2014), allowing us to estimate $\mathrm{CO}_{2}$ uptake by the oceans. From global measurements of $\mathrm{CO}_{2}$ and its isotopic composition, it is clear that $\mathrm{C}$ emitted from industrial activities (Boden et al., 2009) and human land use (Houghton, 1995) has led to the accumulation of $\mathrm{CO}_{2}$ in the atmosphere and $p \mathrm{CO}_{2}$ in the oceans.

Even though our understanding of the global $\mathrm{C}$ cycle has benefited tremendously from this unprecedented global $\mathrm{C}$ monitoring network, we continue to struggle with errors in our measurements and estimates of terms in the global $\mathrm{C}$ budget that limit our ability to draw confident conclusions regarding changes in net $\mathrm{C}$ uptake by the biosphere. As we enter into an era in which scientists are expected to provide an increasingly more detailed assessment of $\mathrm{C}$ uptake at increasingly higher spatial and temporal resolutions (Canadell et al., 2011), it is critical that we develop a framework for the incorporation and propagation of spatial and temporal errors into our calculations to prioritize future research efforts. Furthermore, it is imperative that explicit uncertainties in the global carbon budget be made available to policy makers so that our best estimates can be weighted by levels of uncertainty such that the most informed policy decisions can be made.

The objective of this synthesis is to identify the major sources of error in the important terms of the global $\mathrm{C}$ budget and to assess how these errors affect calculations of net global C uptake by the biosphere and the partitioning of uptake between land and ocean sinks. Although this is an attempt to fully incorporate errors into global C cycle analyses, we acknowledge that there are latent sources of error that remain unknown and are difficult to incorporate into our analysis at this time. However, the framework that we develop here for incorporating both the spatial and temporal error structure is flexible and can be used to incorporate additional sources of error as our knowledge of the global $\mathrm{C}$ budget progresses. The ultimate goal of this analysis is to identify and incorporate all known sources of error into the global $\mathrm{C}$ budget and provide conclusions with confidence intervals of changes in C uptake over the observational period from 1959 to 2010.

\subsection{Important terms of the global carbon budget}

Prior to identifying the main sources of error in the global carbon budget, it is necessary to describe the key processes controlling changes in atmospheric $\mathrm{CO}_{2}$ concentrations. Ac- cording to the mass balance of the atmosphere,

$\frac{\mathrm{d} C}{\mathrm{~d} t}=E_{\mathrm{F}}+E_{\mathrm{L}}+N_{\mathrm{O}}+N_{\mathrm{L}}$,

where $\frac{\mathrm{d} C}{\mathrm{~d} t}$ represents the annual growth rate of atmospheric $\mathrm{CO}_{2}, E_{\mathrm{F}}$ represents the one-way flux of fossil fuel emissions, including cement production, to the atmosphere (Andres et al., 2012), and $E_{\mathrm{L}}$ represents land use emissions to the atmosphere (Houghton et al., 2012). Atmospheric $\mathrm{CO}_{2}$ is constantly being exchanged between the atmosphere and the biosphere, and $N_{\mathrm{L}}$ represents net $\mathrm{C}$ exchange by the land through photosynthesis and respiration and $N_{\mathrm{O}}$ represents net $\mathrm{C}$ exchange by the ocean through air-sea gas exchange. Although land use emission estimates were originally derived to capture $\mathrm{C}$ emissions as a result of clearing primary forest, the operational definition of $E_{\mathrm{L}}$ has expanded to include deforestation and processes affecting forest regrowth, such as $\mathrm{CO}_{2}$ fertilization and $\mathrm{N}$ deposition (Houghton et al., 2012). These different processes incorporated into the $E_{\mathrm{L}}$ term are difficult to disentangle and quantify on the global scale, and thus their combined uncertainty is considered in our error analysis. Because we have defined the global $\mathrm{C}$ mass balance with respect to the atmosphere, all emission terms $(E)$ add $\mathrm{C}$ to the atmosphere and thus have a positive sign, whereas the net exchange terms $(N)$ can have a negative sign indicating net $\mathrm{C}$ uptake from the atmosphere or a positive sign indicating net $\mathrm{C}$ release to the atmosphere. All of the terms in the budget can be measured directly or estimated with an annual time step, except the net land uptake term (i.e., $N_{\mathrm{L}}$ ) that is inferred as the residual land $\mathrm{C}$ sink. Thus, here we consider the statistical error associated with the measurement (e.g., $\mathrm{CO}_{2}$ ) or estimates (e.g., $E_{\mathrm{F}}$ and $E_{\mathrm{L}}$ ) of each term in the global C budget (see Eq. 1 and Fig. 1).

Below, we provide a brief overview of the sources of error in the measurement of the growth of atmospheric $\mathrm{CO}_{2}$ and each of the terms in the carbon budget. We then construct a global carbon budget with a full accounting and propagation of error using a Monte Carlo type approach. To separate ocean and land uptake, we rely on ocean models constrained by observations. We conclude with a discussion of the important sources of error and their impact on uncertainties in calculating land and ocean $\mathrm{C}$ uptake.

\subsection{Sources of error in global atmospheric $\mathrm{CO}_{2}$ measurements}

Most of the error associated with calculating annual changes in the concentration of atmospheric $\mathrm{CO}_{2}$ (i.e., $\frac{\mathrm{d} C}{\mathrm{~d} t}$ ) on the global scale is not due to instrumental accuracy or precision, but rather due to sampling error resulting from the number and locations of sampling sites in the global atmospheric $\mathrm{CO}_{2}$ observing network (Conway et al., 1994). Until recently, measurements of atmospheric $\mathrm{CO}_{2}$ were made primarily using infrared gas analyzers that have a reported accuracy of $0.3 \mathrm{ppm}$, reproducibility of $0.5 \mathrm{ppm}$, and precision 
of approximately $0.05 \mathrm{ppm}$ (Conway et al., 1994; Keeling, 1960). However, because measurements of atmospheric $\mathrm{CO}_{2}$ are made across a spatially heterogeneous network of sites, errors in quantifying changes in atmospheric concentration of $\mathrm{CO}_{2}$ may occur. Although it is possible to control for local contamination by only using background sites located within the marine boundary layer, errors still arise as a result of where atmospheric $\mathrm{CO}_{2}$ measurements are made. As the atmospheric growth rate of $\mathrm{CO}_{2}$ has increased, the uncertainty in the growth rate has gone down due to the addition of sampling sites to the global $\mathrm{CO}_{2}$ observing network. Although recent advances in laser technology have greatly increased the precision and frequency of gas phase $\mathrm{CO}_{2}$ measurements, ultimately our ability to resolve changes in atmospheric $\mathrm{CO}_{2}$ concentration and attribute them to regional fluxes may still be limited by the spatial distribution of sites in the global $\mathrm{CO}_{2}$ observatory.

\subsection{Sources of error in global oceanic $p \mathrm{CO}_{2}$ measurements}

Just as sampling errors associated with atmospheric $\mathrm{CO}_{2}$ measurements may lead to uncertainty in our estimates of the atmospheric growth rate, errors associated with $p \mathrm{CO}_{2}$ measurements and their locations may lead to uncertainty in estimates of global ocean $\mathrm{C}$ uptake. Ocean $\mathrm{C}$ uptake is estimated as a function of the differences in partial pressure between the atmosphere and the ocean $\left(\Delta p \mathrm{CO}_{2}\right)$, as well as the kinetics of $\mathrm{CO}_{2}$ gas transfer and solubility. Uncertainty in net ocean $\mathrm{C}$ uptake is most sensitive to errors in the long-term $p \mathrm{CO}_{2}$ trend, but other factors such as wind speed and sea surface temperature that affect the kinetics of air-sea gas exchange are also important (Wanninkhof et al., 2013). The partial pressure of $\mathrm{CO}_{2}$ in the ocean is much more variable than in the overlying atmosphere. Because $p \mathrm{CO}_{2}$ values vary by as much as $100 \mu \mathrm{atm}$ on seasonal to interannual timescales and become spatially uncorrelated at $10^{2} \mathrm{~km}$, extrapolating $p \mathrm{CO}_{2}$ values is statistically challenging ( $\mathrm{Li}$ et al., 2005). Although statistical techniques for extrapolating $p \mathrm{CO}_{2}$ and estimating $\mathrm{C}$ uptake by the oceans are improving (e.g., Landschützer et al., 2013; Rödenbeck et al., 2013), researchers often rely on ocean biogeochemical models to expand inference to the global scale (Le Quéré et al., 2010, 2013). The largest uncertainty in estimating the net global exchange of $\mathrm{CO}_{2}$ between the ocean and the atmosphere is due to the assumption that $p \mathrm{CO}_{2}$ in the ocean changes at the same rate as $p \mathrm{CO}_{2}$ in the atmosphere, leading to a time-invariant $\Delta p \mathrm{CO}_{2}$. However, studies suggest that $\Delta p \mathrm{CO}_{2}$ is not constant and may have decreased in recent decades in the North Atlantic, resulting in decreased $\mathrm{C}$ uptake (Schuster and Watson, 2007), and may have increased recently in the Pacific, resulting in increased C uptake (Le Quéré et al., 2010). Difficulties also arise in extrapolating estimates of ocean $\mathrm{C}$ uptake to the Southern Hemisphere where observational constraints on simulations are sparse (Lenton et al., 2013) and in coastal

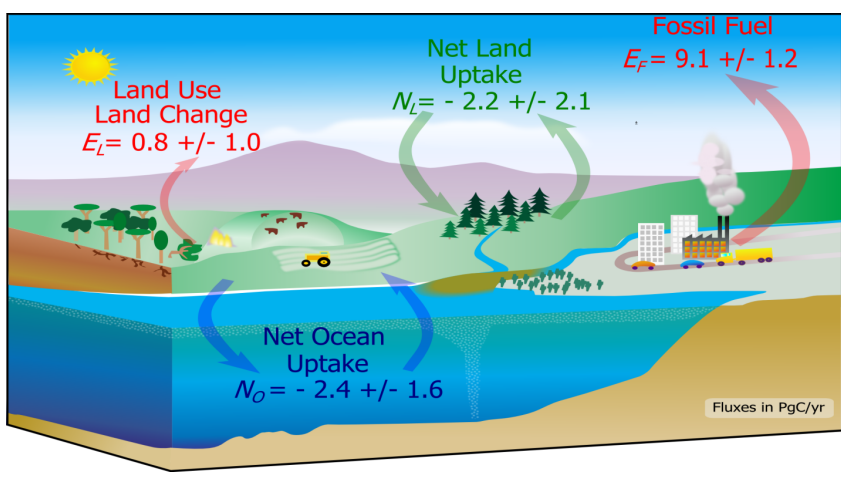

Figure 1. Diagram of the global carbon budget in the year 2010 . Major fluxes of $\mathrm{C}$ to the atmospheric reservoir of $\mathrm{CO}_{2}$ are from fossil fuel emissions $\left(F_{\mathrm{F}}\right)$ and land use land conversion $\left(F_{\mathrm{L}}\right)$ and are illustrated as red vectors. Net land $\left(N_{\mathrm{L}}\right)$ uptake of $\mathrm{C}$ from the reservoir of atmospheric $\mathrm{CO}_{2}$ is illustrated by green vectors and net ocean uptake $\left(N_{\mathrm{O}}\right)$ is illustrated by blue vectors. The size of the vectors is proportional to the mass flux of $\mathrm{C}$ as indicated in petagrams of $\mathrm{C}$ per year, where $1 \mathrm{Pg}=10^{15} \mathrm{~g}$ (illustration modified from Wikimedia Commons). Error estimates for each flux in 2010 are expressed as $\pm 2 \sigma$.

regions that may be affected by continental delivery of dissolved inorganic $\mathrm{C}$ or complex upwelling patterns (Dai et al., 2013). The overall $2 \sigma$ uncertainty in $C$ uptake by the ocean has been estimated empirically from atmospheric $\mathrm{O}_{2}$ to be between 1.2 and 1.4 $\mathrm{PgC} \mathrm{yr}^{-1}$ (Ishidoya et al., 2012; Manning and Keeling, 2006), which is slightly higher than the $2 \sigma$ uncertainty of $1.0 \mathrm{Pg} \mathrm{Cyr}^{-1}$ based on estimates from ocean biogeochemical models (Le Quéré et al., 2013).

\subsection{Sources of uncertainty in estimating fossil fuel emissions}

The greatest contributor to the increase in atmospheric $\mathrm{CO}_{2}$ over the last 50 years is emissions from the combustion of fossil fuels and cement production $\left(E_{\mathrm{F}}\right)$, and therefore errors associated with these emission estimates have the potential to result in large uncertainties in the global $\mathrm{C}$ budget. Global emissions of fossil fuels have increased significantly during the last 5 decades, but relative errors of fossil fuel emission estimates have also increased, leading to a substantial increase in the uncertainty of fossil fuel emissions (Ballantyne et al., 2012). Although our understanding of sources of error in fossil fuel emission estimates has greatly improved, emissions are increasing faster in nations with less accurate emission estimates, thus leading to an increase in both relative and absolute errors of global fossil fuel emissions (Andres et al., 2014, 2012). Because fossil fuel emissions are often estimated from energy consumption or production statistics, they are a fairly well constrained economic variable. Nonetheless, there are two primary sources of error that lead to uncertainties among and within fossil fuel emission inventories. 
First, methodological differences in how energy consumption statistics are converted to $\mathrm{CO}_{2}$ emissions may lead to different fossil fuel emission estimates among different inventories. Most global fossil fuel inventories include emission estimates from solid, liquid, and gas fossil fuels, but the emission coefficients used to convert fossil fuel consumption to $\mathrm{CO}_{2}$ emissions may vary among inventories (Andres et al., 2012). Furthermore, fossil fuel inventories may also differ in their inclusion or treatment of estimated emissions from cement production, gas flaring, and bunker fuels used for international transport. These slight differences in how inventories treat industrial emissions can lead to significant differences in estimates among inventories. While global fossil fuel inventories often rely on similar energy statistics, slightly different methodological approaches employed by different inventories can result in considerably different estimates of global fossil fuel emissions; thus, quasi-independent fossil fuel emission estimates contribute to the global fossil fuel emission uncertainty.

The second major source of error in fossil fuel emission estimates is due to emission accounting practices of individual countries. It has long been suspected that emission reporting practices of developing nations are less reliable than reporting practices from developed nations (Marland et al., 2009). Another important characteristic of the error structure in emission estimates is that some components of the emission errors may be temporally correlated from year to year (Ballantyne et al., 2012; Marland et al., 2009). The global $2 \sigma$ relative uncertainty on the flux-weighted fossil fuel emission estimates is thought to range between 5 and $10 \%$. Thus it is clear that slight discrepancies in fossil fuel emission estimates may lead to potentially large impacts on the inferred global C uptake (Francey et al., 2013).

\subsection{Sources of uncertainty in estimating land use change emissions}

Although emissions from changes in land use and land cover (i.e., $E_{\mathrm{L}}$ ) contribute a smaller fraction to total emissions of atmospheric $\mathrm{CO}_{2}$, relative errors in estimating $E_{\mathrm{L}}$ remain quite high, and thus errors in land use emission estimates can result in large uncertainties in carbon uptake estimates. In the 1950 s approximately $30 \%$ of total $\mathrm{CO}_{2}$ emissions to the atmosphere were from land use change compared to the last decade, in which only $10 \%$ of the total emissions were from land use change. This reduction in the fraction of emissions due to land use change is largely the result of significant increases in fossil fuel emissions combined with nearly constant land use emissions over the last 50 years (Houghton et al., 2012). There are two different approaches to estimating emissions from changing patterns in land use and land cover change (LULCC): bookkeeping and process-based models.

Bookkeeping techniques involve integrating either census or satellite data on forestry and agriculture with data on carbon densities to calculate sources and sinks of carbon based on empirical models (DeFries et al., 1999; Houghton, 1995). The second approach uses process-based ecosystem models to estimate carbon densities and rates of change in these densities as a result of the same drivers of LULCC (i.e., forestry and agriculture) (Stocker et al., 2011; Yang et al., 2010). The major difference between these two approaches is that process-based models include the effects of environmental change (e.g., $\mathrm{CO}_{2}$, climate, $\mathrm{N}$ deposition) on rates of decomposition and growth, while in the bookkeeping approach these rates are constant through time. Each of these approaches attempts to capture the net effect of $\mathrm{C}$ release from deforestation and $\mathrm{C}$ uptake in forest regrowth. Based on this broader definition of LULCC emissions, it is clear that LULCC processes can be treated as emissions (i.e., $E_{\mathrm{L}}$ ) or they could be included in the net land exchange term (i.e., $N_{\mathrm{L}}$ ). Here we consider LULCC emissions explicitly in the $E_{\mathrm{L}}$ term, but this algebraic arrangement does not affect our error analysis. Factors contributing to errors in LULCC emission estimates can be separated into uncertainty in agricultural areas and rate of change in agricultural and forested areas, $\mathrm{C}$ density of natural and agricultural lands undergoing change, and uncertainty stemming from the definition of LULCC emissions (Gasser and Ciais, 2013; Pongratz et al., 2014). Emission estimates derived from these different approaches may differ by as much as $30 \%$ and overall relative $2 \sigma$ errors in these individual approaches may be as high as $50 \%$ (Houghton et al., 2012). Therefore, even though $\mathrm{CO}_{2}$ emissions associated with land use change contribute a decreasingly smaller fraction of total $\mathrm{CO}_{2}$ emissions, land use emission errors remain relatively high.

\section{Methods: identifying sources of error AND uncertainty in the global carbon budget}

\subsection{Errors in calculating the atmospheric growth rate}

Documenting changes in global $\mathrm{CO}_{2}$ concentrations based on atmospheric observations is not trivial, but fortunately the global observation network has expanded over the last 50 years, allowing us to estimate changes in $\frac{\mathrm{d} C}{\mathrm{~d} t}$ with greater confidence. Thus the error in estimating the atmospheric growth rate can be described as follows:

$\frac{\hat{\mathrm{d} C}}{\mathrm{~d} t}=\frac{\mathrm{d} C}{\mathrm{~d} t} \times\left(1+\varepsilon_{c}\right)$,

where $\frac{\hat{\mathrm{d} C}}{\mathrm{~d} t}$ represents our estimate of the true annual growth rate of atmospheric $\mathrm{CO}_{2}\left(\frac{\mathrm{d} C}{\mathrm{~d} t}\right)$ and is calculated as the mean December and January (MDJ) concentrations of atmospheric $\mathrm{CO}_{2}$ minus the MDJ values from the previous year (Thoning et al., 1989). Although atmospheric $\mathrm{CO}_{2}$ is relatively well mixed on timescales greater than 1 year (Conway et al., 1994), there is considerable spatial and temporal error $\left(\varepsilon_{c}\right)$ associated with estimating $\frac{\hat{\mathrm{d} C}}{\mathrm{~d} t}$ on annual timescales. For a 
direct comparison with other terms in the global $\mathrm{C}$ budget, molar mixing ratios of atmospheric $\mathrm{CO}_{2}$ are converted to a mass of petagrams $\left(\mathrm{Pg}=10^{15} \mathrm{~g}\right) \mathrm{C}$ using the conversion factor 2.124 $\mathrm{Pg} \mathrm{C} \mathrm{ppm}^{-1}$ (Sarmiento et al., 2010).

\subsubsection{Spatial error component of the atmospheric $\mathrm{CO}_{2}$ growth rate}

Most of the error associated with calculating the changes in atmospheric $\mathrm{CO}_{2}$ concentration from year to year is due to seasonal heterogeneities in the atmospheric mixing of atmospheric $\mathrm{CO}_{2}$ and the spatial unevenness of the global observing network (http://www.esrl.noaa.gov/gmd/ccgg/). In fact, through cross-validation of individual sites using the entire global network (Masarie and Tans, 1995), errors associated with the sampling network have been estimated to be about 1.2 Pg C, which makes it challenging to substantiate annual growth rates that may only vary between 1 and $2 \mathrm{PgC} \mathrm{yr}^{-1}$ during early parts of the observational record (Ballantyne et al., 2012; Conway et al., 1994; Keeling et al., 1995).

To assess how much $\varepsilon_{C}$ varies as a function of the nonrandom spatial distribution of the global observation network, we first subset the global network for "background" sites in the marine boundary layer (MBL; see Fig. 2) that are less affected by local anomalies in fossil fuel emissions and uptake (Masarie and Tans, 1995). To assess how biases in the MBL network may affect $\varepsilon_{C}$, bootstrap simulations were performed by simulating 100 alternative observation networks consisting of 40 sites that are resampled with replacement from sites located in the MBL. The only geographic constraint on resampling is that at least one site from the tropics, Arctic, Antarctic, North Pacific, and North Atlantic must be included in each simulated network. Since 1980, $\frac{\hat{\mathrm{d} C}}{\mathrm{~d} t}$ has been calculated from all 100 simulated observation networks drawn from the MBL sites.

\subsubsection{Temporal error component of the atmospheric $\mathrm{CO}_{2}$ growth rate}

Because complete mixing of atmospheric $\mathrm{CO}_{2}$ may take more than a year, errors in $\frac{\mathrm{d} C}{\mathrm{~d} t}$ are not independent from year to year. In fact, errors in MDJ ( $\varepsilon_{\text {MDJ }}$ ) values show considerable interannual positive autocorrelation, such that $\varepsilon_{\mathrm{MDJ}(t)}=0.244 \varepsilon_{\mathrm{MDJ}(t-1)}+0.086 \varepsilon_{\mathrm{MDJ}(t-2)}+\varepsilon_{(t)}$, where $\varepsilon_{(t)}$ represents random error in the current year (Ballantyne et al., 2012). Because MDJ values that are biased high lead to $\frac{\mathrm{d} C}{\mathrm{~d} t}$ estimates that are biased high in the previous year and biased low in the subsequent year, this leads to a negative autocorrelation, such that $\varepsilon_{C(t)}=-0.413 \varepsilon_{C(t-1)}-0.166 \varepsilon_{C(t-2)}-$ $0.085 \varepsilon_{C(t-3)}+\varepsilon_{(t)}$. Over the period prior to $1980, \frac{\hat{\mathrm{d} C}}{\mathrm{~d} t}$ was calculated from atmospheric $\mathrm{CO}_{2}$ observations at Mauna Loa and the South Pole (MLOSPO) and $\varepsilon_{C}$ was estimated from

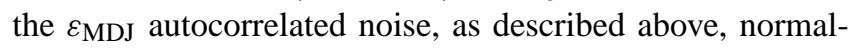
ized to a standard deviation of $0.24 \mathrm{ppm}$ based on the period of observational overlap between MLOSPO and the MBL.
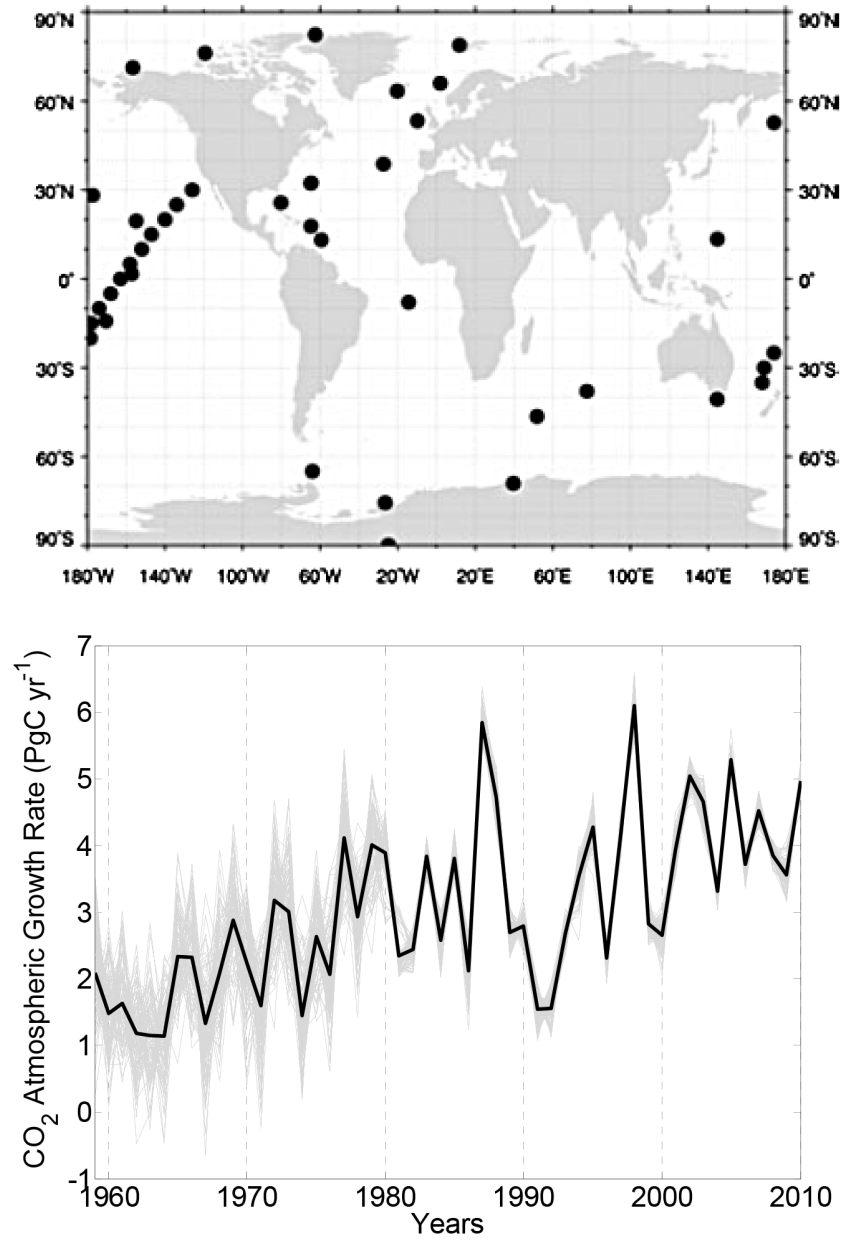

Figure 2. The global observation network used in calculating the annual atmospheric $\mathrm{CO}_{2}$ growth rate. The annual growth rate of atmospheric $\mathrm{CO}_{2}$ is calculated from resampling sites in the global network located in the marine boundary layer (black points; top panel). The annual growth rate since 1980 is calculated from the entire marine boundary layer, while the growth rate prior to 1980 is calculated from observation sites at Mauna Loa, Hawaii, USA, and the South Pole, Antarctica. The mean atmospheric growth rate is illustrated as a thick black line and growth rates calculated from the 100 simulated sampling networks are illustrated by the thin grey traces.

Monthly mean MLOSPO values prior to 1974 were calculated from Scripps Institution of Oceanography data (Keeling et al., 2005), and monthly mean MBL values were calculated from data collected by the National Oceanic and Atmospheric Administration's Earth System Research Laboratory (http://www.esrl.noaa.gov/). 


\subsection{Errors and uncertainties in fossil fuel emission estimates}

The process that currently accounts for the greatest flux of $\mathrm{CO}_{2}$ to the atmosphere is the combustion of fossil fuels and cement production (i.e., $E_{\mathrm{F}}$ ). Because fossil fuel emission estimates are derived from economically constrained statistics of energy production and consumption, the relative errors in fossil fuel emission estimates are fairly small and typically between 5 and $10 \%$ (Andres et al., 2014). However, because fossil fuel emissions currently account for $>90 \%$ of total emissions, even relatively small errors can result in potentially large uncertainties in absolute $\mathrm{C}$ uptake calculated on the global scale (Francey et al., 2013; although see Raupach et al., 2013). Therefore, identifying the sources of error in fossil fuel emission estimates $\hat{E}_{\mathrm{F}}$ is critical to constraining uncertainty in the global carbon budget:

$\hat{E}_{\mathrm{F}}=E_{\mathrm{F}} \times\left(1+\varepsilon_{\mathrm{F}}\right)$,

where $\varepsilon_{\mathrm{F}}$, the error factor in estimating fossil fuel emissions, has both a spatial and temporal component.

\subsubsection{Spatial error component of fossil fuel emissions}

There are many sources of error in estimating fossil fuel emissions. In particular, fossil fuel emission inventories differ in their inclusion of $\mathrm{CO}_{2}$ emissions from cement production and international transport, as well as their treatment of gas flaring (Andres et al., 2012). These subtle differences can equate to considerable discrepancies between different inventories (Fig. 3). Another significant source of error in global emission inventories is due to the different accounting practices of different nations. Although emission inventories are often based on standardized surveys of energy consumption, different institutions have different protocols for missing data and how units of energy are converted into $\mathrm{CO}_{2}$ emissions (Andres et al., 2012). In some instances there may even be large discrepancies between the sum of provincial emission estimates and national emission estimates (Guan et al., 2012). All of these factors lead to uncertainties in emission estimates. While there is a general consensus that emission errors in developed nations are much lower than in developing nations, emissions are increasing at a faster rate simply because these nations are developing rapidly.

For this analysis, countries were grouped into geographic regions as specified by the United Nations Statistics Division (http://unstats.un.org/unsd/methods/m49/m49regin. $\mathrm{htm}$ ). Uncertainties for each country (see Supplement, Table S1; Andres et al., 2014) were used to create regional maximum error distributions for each emission inventory using a bootstrapping method, with the highest emitters within the region contributing the most to the error distributions. This effect was achieved by weighting the sampling probability $(P(s))$ by the relative contribution of each country's
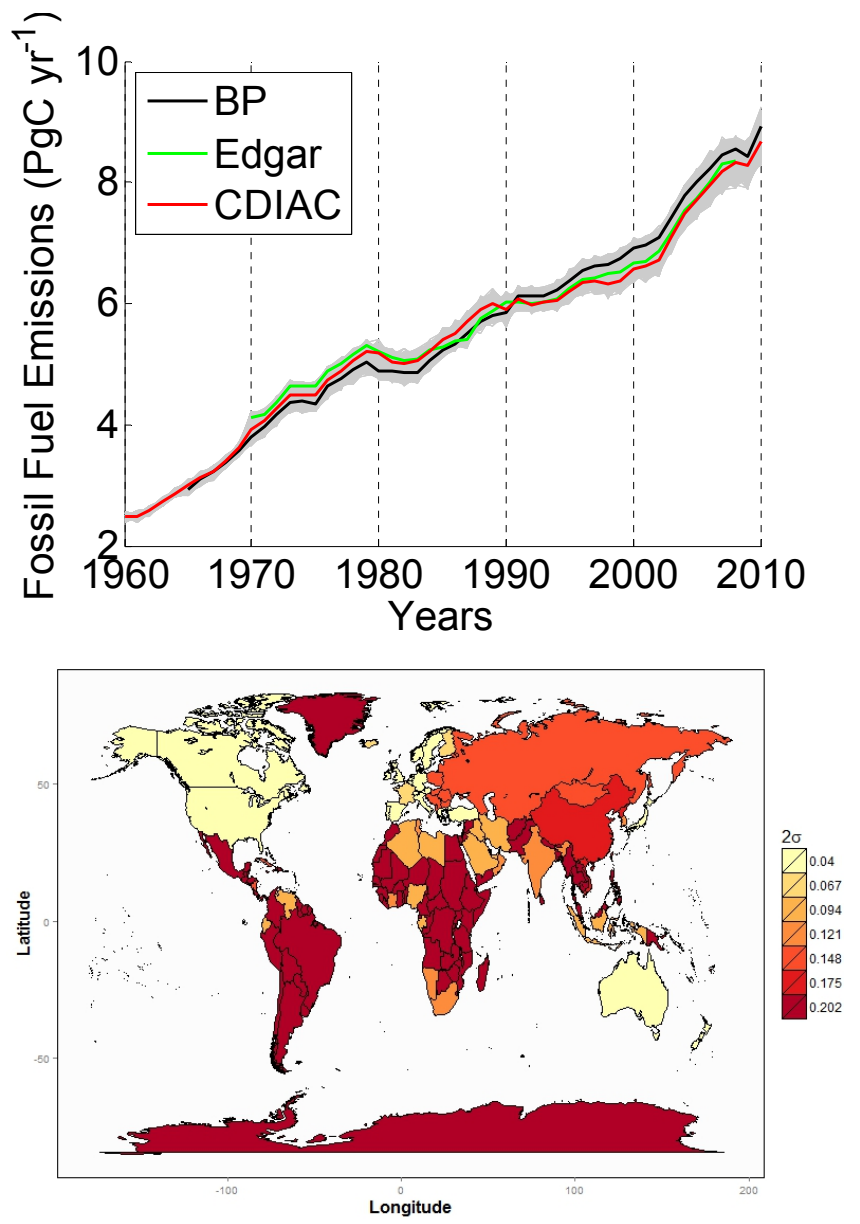

Figure 3. Fossil fuel emission estimates and their uncertainties from 1960 to 2010. The three inventories (top panel) compared are from BP (British Petroleum; black), the Emission Database for Global Atmospheric Research (EDGAR: green), and the Carbon Dioxide Information and Analysis Center (CDIAC; red). All inventories also include cement production. Thin grey traces represent the Monte Carlo simulations of uncertainty for the fossil fuel emission inventories $(N=3 \times 500=1500)$. Errors are estimated by deriving regional error distributions and then randomly drawing from these distributions for error estimates of individual nations (bottom panel) where error estimates are modified from Andres et al. (2014). Emission errors are reported as relative errors of total emissions by nation, and emission errors for Antarctica are for the Antarctic fishing fleet. See Supplement, Table 1, for national errors.

emissions $\left(E_{C}\right)$ to the total emissions within that region $\left(E_{R}\right): P(s)=E_{C} / E_{R}$.

The bootstrapping method used 1000 iterations of the mean of sampled errors to produce a smoothed distribution for regional maximum errors. This method allows for bounded fluctuations in country-level annual errors that relate directly to regional errors. To constrain the temporal component of the emission errors (Sect. 2.2.2), 10 random samples were drawn from the corresponding error distribu- 
tion for each country for each year from 1959-2010, producing 10 random relative error time series for each country. These time series were used to produce the autocorrelated time series as described in Sect. 2.2.2.

\subsubsection{Temporal error component of fossil fuel emissions}

Fossil fuel accounting practices differ by individual nations, but these accounting practices often change over time as well. The errors in annual emission estimates are not independent from year to year. For instance, if an error is identified in annual emission calculations of a given country, then this error is corrected for the current year and all previous years' emission estimates may be retroactively corrected (Marland et al., 2009). Thus the errors in annual emission estimates are not necessarily independent over time. To account for this potential time-dependent error, we modified the conventional Monte Carlo approach, in which errors are randomly drawn for each year of the simulation to account for the known autocorrelation of errors in emission inventories. To distinguish this approach from the conventional Monte Carlo approach, we refer to it as an "el camino" method in which errors in the current year are dependent upon errors in previous years and thus the temporally correlated errors follow a "path" from year to year. This el camino approach allows for the incorporation of autocorrelated random noise into our fossil fuel emissions, such that

$\varepsilon_{F(t)}=0.95 \times \varepsilon_{F(t-1)}+\varepsilon_{(t)}$,

where emission error factors for any given year $\varepsilon_{F(t)}$ are correlated with emission estimates from the previous year $\varepsilon_{F(t-1)}$ by an autoregressive coefficient of 0.95 with $\varepsilon_{(t)}$ as random error. Based on this formulation, the persistence of autocorrelation among errors in successive years is $\sim 20$ years. We note that our selection of $\sim 20$ years for the persistence of autocorrelation in emission error estimates is somewhat arbitrary; it assumes that errors are not corrected retroactively after 20 years. While it is conceivable that emission errors could be corrected going back even further in time, it has been shown that estimates tend to converge after a decade (Marland et al., 2009); therefore, 2 decades is a fairly conservative estimate of the time dependence of errors. For our analysis, we relied on three independent fossil fuel emission inventories (Fig. 3) - BP (previously known as British Petroleum), the Carbon Dioxide Information and Analysis Center (CDIAC), and the Emission Database for Global Atmospheric Research (EDGAR) - all of which included cement production as a source of emissions.

\subsection{Errors and uncertainties in land use emission estimates}

Among the variables in the global carbon budget (Eq. 1), $\mathrm{CO}_{2}$ emissions from land use and land change $\left(E_{\mathrm{L}}\right)$ are probably the most difficult to quantify and have the greatest error.
This is because the net flux from $E_{\mathrm{L}}$ encompasses emissions resulting from the conversion of land from primary forest to agricultural land, in addition to $\mathrm{C}$ uptake associated with the abandonment of agricultural lands and the regrowth of secondary forest (Houghton, 1995). Many of these processes occur on local to regional scales; thus, these errors are difficult to propagate to the global scale. However, rates of deforestation and regrowth have changed over time, and other environmental processes, such as $\mathrm{N}$ deposition, climate variability and $\mathrm{CO}_{2}$ fertilization may alter these rates (Jain et al., 2013). Here we consider the main factors contributing to the spatial and temporal components of $E_{\mathrm{L}}$, such that

$\hat{E}_{\mathrm{L}}=E_{\mathrm{L}} \times\left(1+\varepsilon_{\mathrm{L}}\right)$.

\subsubsection{Spatial error component of land use emissions}

Land use emissions have remained fairly constant, or may have diminished, over the past 20 years, but patterns of deforestation associated with these emissions have clearly changed (Hansen et al., 2013; Houghton et al., 2012). Although recent estimates from Landsat imagery indicate that deforestation in Brazil has indeed gone down by approximately $1300 \mathrm{~km}^{2} \mathrm{yr}^{-1}$ in Brazil from 2000 to 2010 the last decade, this has almost been compensated for by a $1000 \mathrm{~km}^{2} \mathrm{yr}^{-1}$ increase in deforestation rates in Indonesia over the same period (Hansen et al., 2013), suggesting a regional shift in land use emissions but very little net change in global land use change emissions over the last decade (Houghton et al., 2012). However, there are errors and assumptions associated with the conversion of forest area into $\mathrm{CO}_{2}$ emission equivalents, and the $2 \sigma$ relative uncertainties on emission estimates from land use change are thought to be on the order of $50 \%$ (R. A. Houghton, personal communication, 2012).

\subsubsection{Temporal error component of land use emissions}

Similar to errors in fossil fuel emission estimates, errors in $\mathrm{CO}_{2}$ emissions from land use are also serially correlated. The benchmark method for estimating emissions from land use is the bookkeeping approach developed by Houghton (1983) that is based on global forestry statistics that are only released every 5 years (FAO, 2010). Thus net land use emissions must be extrapolated for intervening years when no forestry statistics are available. Although this interpolation approach works fairly well when rates of deforestation and regrowth are not changing, this approach can lead to errors in estimating land use emissions that once again are corrected retroactively. Therefore, we apply a similar el camino approach to simulating the autocorrelated errors in land use emissions by using the following relationship:

$\varepsilon_{L(t)}=0.05 \times \varepsilon_{L(t-1)}+\varepsilon_{(t)}$,

where the persistence of temporally correlated errors in land use emission is reduced to $\sim 5$ years. While this time per- 


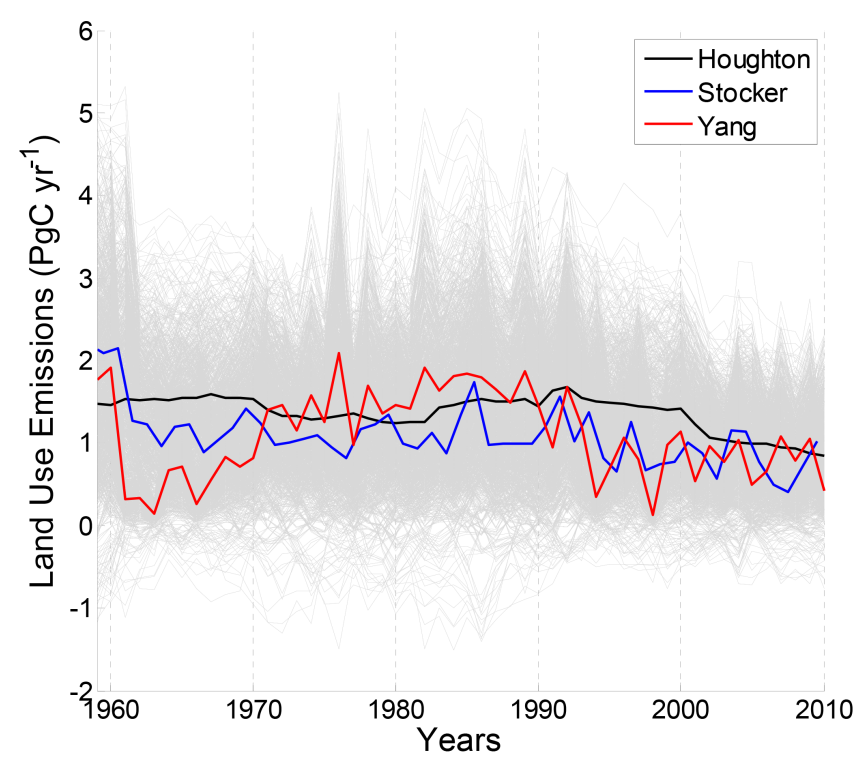

Figure 4. Comparison of land-use-land-change emission inventories from 1960 to 2010. The three inventories compared are the bookkeeping approach (Houghton et al., 2012; black), modelderived estimates including historical land use (Stocker et al., 2013: blue), and model-derived estimates, including historical land use and nitrogen cycling (Yang et al., 2010; red). Thin grey traces represent the Monte Carlo simulations of uncertainty for the land use emission estimates $(N=3 \times 500=1500)$.

sistence value is also arbitrary, it was selected based on the Food and Agricultural Organization's forestry statistics that are updated every 5 years. Therefore, land use emission estimates are predicted into the future 4 years and then corrected retroactively in the fifth year (Friedlingstein et al., 2010). Here we consider three independent estimates of $E_{\mathrm{L}}$ derived from three different approaches: (1) the bookkeeping method based on forestry statistics (Houghton, 1995), (2) a model-derived estimate based on historical land use maps (Stocker et al., 2011), and (3) a model-derived estimate including historical land use as well as nitrogen cycling (Yang et al., 2010). Although more $E_{\mathrm{L}}$ estimates exist, we have selected three representative estimates of $E_{\mathrm{L}}$ covering a range of possible approaches for inclusion in our error analysis framework (Fig. 4).

\subsection{Estimating net ocean and land uptake with uncertainty}

\subsubsection{Estimating net global C uptake}

In order to estimate changes in the net global $\mathrm{C}$ uptake, we focused on two diagnostic variables of the global $\mathrm{C}$ cycle. First we calculated net global $C$ uptake by simply rearranging Eq. (1) to solve for

$\Sigma N=\frac{\hat{\mathrm{d} C}}{\mathrm{~d} t}-\Sigma E$, where we calculate net global uptake simply as the difference between the annual atmospheric growth rate and the sum of net emission fluxes to the atmosphere. Because we have defined the $\mathrm{C}$ mass balance with respect to the atmosphere, a net loss from the atmosphere corresponds with negative $\Sigma N$ as a result of increased $\mathrm{C}$ uptake by the biosphere. In order to calculate relative changes in global C uptake efficiency, we also calculated the airborne fraction (AF), according to

$\mathrm{AF}=\frac{\hat{\mathrm{d} C}}{\mathrm{~d} t} / \Sigma E$,

where an increase in AF would indicate an increase in the proportion of emissions remaining in the atmosphere and perhaps diminished $\mathrm{C}$ uptake efficiency by the biosphere.

To incorporate the error from different combinations of our fossil fuel emission simulations $\left(E_{\mathrm{FX}}\right)$ and our land use emission simulations $\left(E_{\mathrm{LX}}\right)$, we devised an emission scenario matrix:

$$
\Sigma E_{(\mathrm{FX}, \mathrm{LX})}=\left[\begin{array}{lll}
E_{\mathrm{F} 1}+E_{\mathrm{L} 1} & E_{\mathrm{F} 1}+E_{\mathrm{L} 2} & E_{\mathrm{F} 1}+E_{\mathrm{L} 3} \\
E_{\mathrm{F} 2}+E_{\mathrm{L} 1} & E_{\mathrm{F} 2}+E_{\mathrm{L} 2} & E_{\mathrm{F} 2}+E_{\mathrm{L} 3} \\
E_{\mathrm{F} 3}+E_{\mathrm{L} 1} & E_{\mathrm{F} 3}+E_{\mathrm{L} 2} & E_{\mathrm{F} 3}+E_{\mathrm{L} 3}
\end{array}\right],
$$

where $\Sigma E_{(\mathrm{FX}, \mathrm{LX})}$ is a flexible framework that can accommodate any number of combinations of emission simulations. In our analysis we only consider three $E_{\mathrm{FX}}$ estimates and three $E_{\mathrm{LX}}$ estimates in our $3 \times 3$ matrix for a total of nine different combinations of fossil fuel and land use emissions. Each combination consists of the sum of 500 fossil fuel emission simulations and 500 land use emission simulations with their associated spatial and temporal error spanning 52 years (ie. 1959 to 2010), for a grand total of $4500 \times 52$ simulations of $\Sigma E_{(\mathrm{FX}, \mathrm{LX})}$ (Fig. 5). In order to calculate $\Sigma N$ and AF, we randomly drew from our $\frac{\mathrm{d} C}{\mathrm{~d} t}$ simulations to perform $4500 \mathrm{calcu}-$ lations of $\Sigma N$ and AF spanning the period of 1959 to 2010. We calculated $\Sigma N$ and AF using two approaches; one using the sum of all emissions as shown in the emission scenario matrix (Eq. 9) and the other using just $E_{\mathrm{F}}$ simulations to assess how sensitive global $\mathrm{C}$ uptake is to these two different $\mathrm{CO}_{2}$ emission scenarios.

\subsubsection{Partitioning $C$ uptake between the land and the ocean}

In order to partition the global net $\mathrm{C}$ uptake flux between net land (i.e., $N_{\mathrm{L}}$ ) and net ocean (i.e., $N_{\mathrm{O}}$ ) uptake, we relied on ocean biogeochemical models that have been constrained by observations (Le Quéré et al., 2013) . In particular, these ocean biogeochemical models have been normalized to changes in atmospheric $\mathrm{O}_{2} / \mathrm{N}_{2}$, which provide an independent estimate of ocean $\mathrm{C}$ uptake mostly expressed on decadal timescales. We extended this logic by using $\mathrm{O}_{2} / \mathrm{N}_{2}$ measurements to estimate the error in estimates of ocean $\mathrm{C}$ uptake in these ocean biogeochemical models:

$\hat{N}_{\mathrm{O}}=N_{\mathrm{O}} \times\left(1+\varepsilon_{\mathrm{O}}\right)$, 


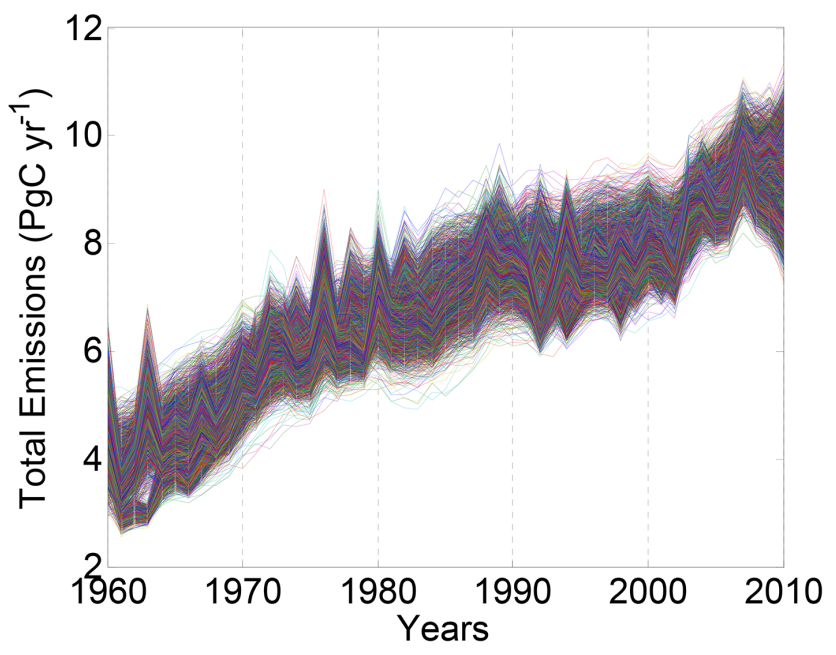

Figure 5. Total emission scenarios including uncertainty. Plotted are all combinations of the sum of land use and fossil fuel emission estimates included in this study A total of 500 realizations for each of the three land use emission estimates and each of the fossil fuel emission estimates is included for a total of 4500 global emission realizations (each colored line).

where $\varepsilon_{\mathrm{O}}$ is the $2 \sigma$ error in ocean $\mathrm{C}$ uptake and is estimated, as the average uncertainty in atmospheric potential oxygen, to be approximately $1.3 \mathrm{Pg} \mathrm{Cyr}^{-1}$ as reported in Ishidoya et al. (2012) and Manning and Keeling (2006). Thus, timeinvariant random normally distributed error $\left( \pm \varepsilon_{\mathrm{O}}\right)$ is added to each year of $\mathrm{C}$ uptake in each of the ocean biogeochemical models included in our analysis. For our analysis we considered ocean $\mathrm{C}$ uptake estimates from five independent ocean biogeochemical models: (1) Nucleus for European Modeling of the Ocean (NEMO), (2) Laboratory of Science and Climate of the Environment (LSCE) ORCA2-LIM model (referred to as "LSCE" in Fig. 6), (3) Community Climate System Model (CCSM-BEC), (4) Norwegian Ocean Biogeochemical Model (MICOM-HAMOCC), and (5) Max Planck Institute for Meterology Ocean Model (MPI-MET); these have all been included in the Global Carbon Project's 2013 assessment (Le Quéré et al., 2013). For each model, the random error term $\left(\varepsilon_{\mathrm{O}}\right)$ was added at each time step for a total of 900 realization of $\mathrm{C}$ uptake with error for each model for a grand total of 4500 realizations across models (Fig. 6). It should be noted that in order to calculate the ocean $\mathrm{C}$ uptake and its uncertainty from atmospheric measurements of $\mathrm{O}_{2} / \mathrm{N}_{2}$, fossil fuel emission estimates are required to constrain the "atmospheric potential oxygen"; thus, the $\varepsilon_{\mathrm{O}}$ and the $\varepsilon_{\mathrm{F}}$ terms are not entirely independent. Nonetheless, $\mathrm{O}_{2} / \mathrm{N}_{2}$ measurements provide a measure of error which can be applied to individual climate model simulations. These ocean $\mathrm{C}$ uptake realizations were then subtracted from our global uptake to infer net land uptake, according to

$\hat{N}_{\mathrm{L}}=\Sigma N-\hat{N}_{\mathrm{O}}$

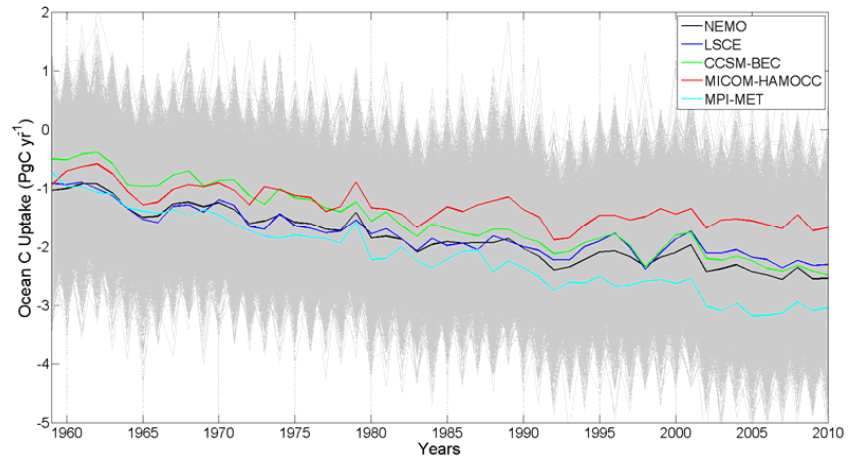

Figure 6. Ocean carbon uptake estimates from five different ocean biogeochemical models. Independent time-invariant random error of $1.3 \mathrm{Pg} \mathrm{C}(2 \sigma)$ has been added to each annual model simulation according to independent estimates of ocean $\mathrm{C}$ uptake (Ishidoya et al., 2012). For each biogeochemical model estimate, 900 Monte Carlo simulations were performed to better estimate error (thin grey lines).

thus yielding a distribution of 4500 simulations of $N_{\mathrm{O}}$, with $N_{\mathrm{L}}$ spanning the 1959 to 2010 observational period. From these simulations we estimate the significance of observed trends in $\Sigma N, N_{\mathrm{O}}, N_{\mathrm{L}}$, and $\mathrm{AF}$ over the last 5 decades as well as decadal changes in the mean value and the variance.

\section{Results: sources of error and their impact on uptake uncertainty}

\subsection{Increasing precision and increasing variability in the atmospheric $\mathrm{CO}_{2}$ growth rate}

The error in calculating the annual atmospheric $\mathrm{CO}_{2}$ growth rate has decreased considerably over the last 5 decades (Fig. 2). The mean overall $2 \sigma$ uncertainty for $\frac{\hat{\mathrm{d} C}}{\mathrm{~d} t}$ was $0.71 \mathrm{PgCyr}^{-1}$, with a much higher $2 \sigma$ uncertainty of $1.11 \mathrm{Pg} \mathrm{C} \mathrm{yr}^{-1}$ from 1959 to 1980 and a much lower $2 \sigma$ uncertainty from 1980 to the present of $0.36 \mathrm{Pg} \mathrm{C} \mathrm{yr}^{-1}$. At the same time the variability in $\frac{\hat{\mathrm{d} C}}{\mathrm{~d} t}$ appears to have increased over the last 50 years. This is most clearly evident when inspecting decadal changes in the standard deviations of the annual mean values of $\frac{\hat{\mathrm{d} C}}{\mathrm{~d} t}$ (Table 1). During the $1960 \mathrm{~s} \frac{\hat{\mathrm{d} C}}{\mathrm{~d} t}$ values were much less variable $\left(\sigma=0.61 \mathrm{PgC} \mathrm{yr}^{-1}\right)$ than values of $\frac{\hat{\mathrm{d} C}}{\mathrm{~d} t}$, which peaked during the $1990 \mathrm{~s}\left(\sigma=1.40 \mathrm{Pg} \mathrm{C} \mathrm{yr}^{-1}\right)$ and have subsequently become slightly less variable since 2000 $\left(\sigma=0.82 \mathrm{PgC} \mathrm{yr}^{-1}\right)$. It is intriguing that variability in $\frac{\hat{\mathrm{dC}} \mathrm{d} t}{\text { ap- }}$ pears to be increasing while our precision in estimating $\frac{\hat{\mathrm{d} C}}{\mathrm{~d} t}$ has also increased. To test whether this increase in $\frac{\hat{\mathrm{d} C} t}{\mathrm{~d} t}$ is simply due to sites being added to the global atmospheric $\mathrm{CO}_{2}$ monitoring network, we examined the standard deviation in the atmospheric growth rate calculated from only the Mauna Loa and the South Pole monitoring sites. Although the over- 
Table 1. Decadal changes in variables of the global C budget. Reported are decadal means for the atmospheric growth rate, land use emissions, fossil fuel emissions, global uptake, the airborne fraction, net ocean uptake, and net land uptake. The first number below the mean (in parentheses) is the mean of the decadal standard deviations that provides a measure of our ability to detect a change in that variable. The second number below the mean (in parentheses) is the standard deviation of the decadal means that provides a measure of variance in that variable.

\begin{tabular}{|c|c|c|c|c|c|}
\hline \multirow[b]{2}{*}{ Variable } & \multicolumn{5}{|c|}{ Decadal mean values and standard deviations } \\
\hline & $1960 \mathrm{~s}$ & 1970 s & $1980 \mathrm{~s}$ & $1990 \mathrm{~s}$ & $2000 \mathrm{~s}$ \\
\hline Atmospheric $\mathrm{CO}_{2}\left(\mathrm{PgC} \mathrm{yr}^{-1} ; \partial C / \partial t\right)$ & 1.75 & 2.72 & 3.42 & 3.18 & 4.14 \\
\hline Mean of standard deviations & $(0.60)$ & $(0.61)$ & $(0.22)$ & $(0.18)$ & $(0.16)$ \\
\hline Standard deviation of the means & $(0.61)$ & $(0.91)$ & $(1.21)$ & $(1.40)$ & $(0.82)$ \\
\hline Land use emissions $\left(\mathrm{PgC} \mathrm{yr}^{-1} ; E_{\mathrm{L}}\right)$ & 1.16 & 1.28 & 1.42 & 1.15 & 0.89 \\
\hline Mean of standard deviations & $(0.76)$ & $(0.64)$ & $(0.65)$ & $(0.67)$ & $(0.63)$ \\
\hline Standard deviation of the means & $(0.25)$ & $(0.11)$ & $(0.13)$ & $(0.23)$ & $(0.12)$ \\
\hline Fossil fuel emissions $\left(\mathrm{PgC} \mathrm{yr}^{-1} ; E_{\mathrm{F}}\right)$ & 3.09 & 4.76 & 5.53 & 6.45 & 7.89 \\
\hline Mean of standard deviations & $(0.15)$ & $(0.24)$ & $(0.30)$ & $(0.35)$ & $(0.47)$ \\
\hline Standard deviation of the means & $(0.44)$ & $(0.41)$ & $(0.33)$ & $(0.24)$ & $(0.69)$ \\
\hline Net global uptake $\left(\mathrm{PgCyr}^{-1} ; \Sigma N\right)$ & -2.51 & -3.32 & -3.61 & -4.38 & -4.64 \\
\hline Mean of standard deviations & $(0.83)$ & $(0.76)$ & $(0.52)$ & $(0.56)$ & $(0.50)$ \\
\hline Standard deviation of the means & $(0.52)$ & $(0.84)$ & $(1.13)$ & $(1.37)$ & $(0.98)$ \\
\hline Airborne fraction $(\mathrm{AF})$ & 0.42 & 0.45 & 0.48 & 0.42 & 0.47 \\
\hline Mean of standard deviations & $(0.16)$ & $(0.11)$ & $(0.05)$ & $(0.04)$ & $(0.03)$ \\
\hline Standard deviation of the means & $(0.12)$ & $(0.14)$ & $(0.16)$ & $(0.18)$ & $(0.10)$ \\
\hline Net ocean uptake $\left(\mathrm{PgC} \mathrm{yr}^{-1} ; N_{\mathrm{O}}\right)$ & -1.11 & -1.43 & -1.79 & -2.07 & -2.21 \\
\hline Mean of standard deviations & $(1.31)$ & $(1.32)$ & $(1.33)$ & $(1.35)$ & $(1.39)$ \\
\hline Standard deviation of the means & $(0.24)$ & $(0.16)$ & $(0.06)$ & $(0.09)$ & $(0.19)$ \\
\hline Net land uptake $\left(\mathrm{PgC} \mathrm{yr}^{-1} ; N_{\mathrm{L}}\right)$ & -1.39 & -1.89 & -1.78 & -2.35 & -2.46 \\
\hline Mean of standard deviations & $(1.56)$ & $(1.51)$ & $(1.43)$ & $(1.46)$ & $(1.43)$ \\
\hline Standard deviation of the means & $(0.56)$ & $(0.90)$ & $(1.17)$ & $(1.48)$ & $(1.06)$ \\
\hline
\end{tabular}

all variance in $\frac{\hat{d C C}}{\mathrm{~d} t}$ was slightly reduced when calculated from only two sites, $\frac{d C}{\mathrm{~d} t}$ estimates show a similar increase in standard deviation from the $1960 \mathrm{~s}\left(\sigma=0.58 \mathrm{Pg} \mathrm{C} \mathrm{yr}^{-1}\right)$ through the $1990 \mathrm{~s}\left(\sigma=1.26 \mathrm{Pg} \mathrm{Cyr}^{-1}\right)$. Thus the apparent increase in carbon cycle variability over the last 50 years seems to be robust and not an artifact of the expanding global atmospheric $\mathrm{CO}_{2}$ observation network.

In the early part of the observation record, errors associated with estimating $\frac{\hat{\mathrm{d} C} \mathrm{~d} t}{\mathrm{~d}}$ were one of the main contributors to uncertainty in calculating global $\mathrm{C}$ uptake; however, as the precision of estimating $\frac{\hat{\mathrm{d} C}}{\mathrm{~d} t}$ has increased, their contribution to global $\mathrm{C}$ uptake uncertainty has been reduced. In fact, in the 1960s errors in the atmospheric $\mathrm{CO}_{2}$ growth rate accounted for roughly $40 \%$ of the uncertainty in global C uptake; in contrast, in the 2000s errors in the atmospheric $\mathrm{CO}_{2}$ growth rate accounted for only about $10 \%$ of the uncertainty in global $\mathrm{C}$ uptake (Fig. 11). Thus, errors in estimating the annual growth rate at the beginning of the period of obser- vation (e.g., 1960s) made it difficult to determine if $\frac{\hat{\mathrm{d} C}}{\mathrm{~d} t}$ was in fact statistically distinguishable from 0 (Fig. 2); however, continued measurements have revealed that not only is $\frac{\hat{\mathrm{dCC}}}{\mathrm{d} t}$ positive, but it is clearly accelerating as a result of increased emissions.

\subsection{Increasing uncertainty in fossil fuel emission estimates}

As of 2010, more than $90 \%$ of the total $\mathrm{CO}_{2}$ emissions to the atmosphere were derived from fossil fuel combustion or cement production (Fig. 1); therefore, slight errors in $E_{\mathrm{F}}$ can have significant impacts on $\mathrm{C}$ uptake estimates by the land and ocean. While fossil fuel emissions have increased by a factor of 3.6 over the past 50 years, the absolute errors in fossil fuel emissions have increased by a factor 4.5 over the same period of time (Fig. 3), suggesting that fossil fuels account for an increasing proportion of the atmospheric $\mathrm{CO}_{2}$ burden but that the precision of our $E_{\mathrm{F}}$ estimates is actually 
decreasing over time. This result is supported by the decadal statistics showing that the mean of the standard deviations has increased from the 1960s to the present, while the standard deviation of the means has not changed appreciably (Table 1). This increase in $E_{\mathrm{F}}$ errors is due to the divergence in independent $E_{\mathrm{F}}$ inventories compounded by a greater contribution of emissions from emerging economies. Estimates of $E_{\mathrm{F}}$ from BP appear to be slightly higher than $E_{\mathrm{F}}$ estimates from CDIAC and EDGAR, which are more similar to each other but were slightly lower over the last 2 decades (Fig. 3). It is not quite clear what differences in accounting practices may cause these slight discrepancies between inventories because they often rely on the same energy consumption statistics (Andres et al., 2012).

The other major source of error in fossil fuel emission estimates is from national reporting statistics that vary considerably based on the degree of development in energy infrastructure (Fig. 3). While $E_{\mathrm{F}}$ errors are relatively low for North America, Europe, Australia, and parts of Asia, they are noticeably higher for some countries that emit a large portion of the global fossil fuel emissions, such as India, China, and Russia. Lastly, the highest emission errors are for countries in South and Central America as well as some countries in Africa and the Middle East. These geographical regions with higher errors are also located in regions with very few observations of atmospheric $\mathrm{CO}_{2}$, making our ability to detect changes in net $\mathrm{C}$ uptake for these regions exceedingly difficult.

Lastly, poorly constrained fossil fuel emission estimates are contributing a larger proportion to global $\mathrm{C}$ uptake uncertainty today than they were 50 years ago (Fig. 11). In the 1960s approximately $10 \%$ of the uncertainty in global $\mathrm{C}$ uptake could be attributed to errors in fossil fuel emission estimates, whereas approximately $30 \%$ of the global C uptake uncertainty is due to fossil fuel emission errors since 2000. Furthermore, increasing trends in the errors of fossil fuel emissions are quickly becoming the dominant factor contributing to global $\mathrm{C}$ uptake uncertainty, with $38 \%$ of the overall uncertainty in global $\mathrm{C}$ uptake due to emission errors in fossil fuels by the year 2010 .

\subsection{Uncertainty in land use emission estimates remains high}

Although emissions from land-use-land-cover change (i.e., $E_{\mathrm{L}}$ ) contribute much less to the total emissions to the atmosphere today than they did 5 decades ago, emission errors (i.e., $\varepsilon_{\mathrm{L}}$ ) remain quite high (Fig. 4). Emissions from LULCC have remained fairly constant over the last 50 years, with an apparent decline over the last 20 years (Table 1). Because $E_{\mathrm{L}}$ has remained fairly constant while $E_{\mathrm{F}}$ has risen steadily over the last 50 years, the fraction of total emissions comprised of $E_{\mathrm{L}}$ has declined to $10 \%$ since the year 2000 , whereas $E_{\mathrm{L}}$ comprised almost $30 \%$ of the total emissions to the atmosphere during the 1960s.

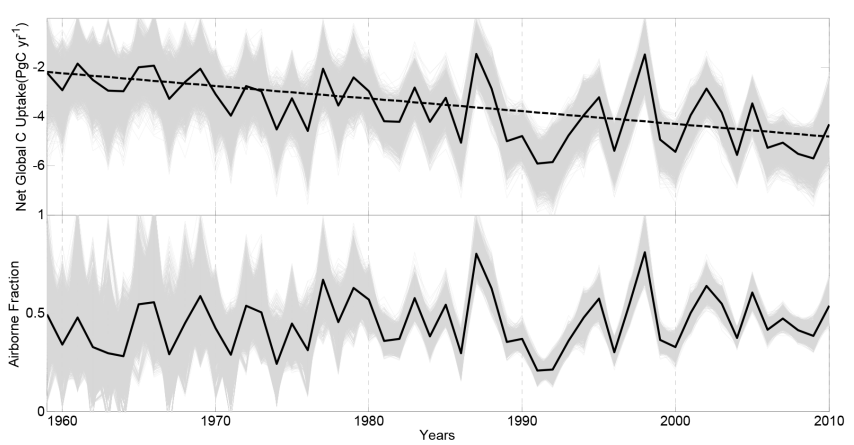

Figure 7. Simulations of net global $\mathrm{C}$ uptake and the airborne fraction from 1959 to 2010 . Net global $\mathrm{C}$ uptake ( $\Sigma N$; top panel) is plotted in comparison to the airborne fraction (AF; bottom panel). A total of 4500 simulations of $\Sigma N$ and AF are plotted in each panel (thin grey lines) and mean annual values are overlaid (thick black line). A significant acceleration in global net $\mathrm{C}$ uptake is indicated

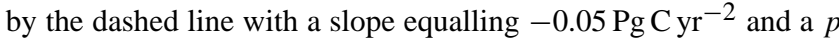
value equalling $5.5 \times 10^{-5}$ fitted to the annual mean $\Sigma N$ values. See Table S2 for global C uptake values and their uncertainty.

Because errors in $E_{\mathrm{L}}$ are often reported as relative errors, they have gone down slightly in recent years as a function of decreasing emissions for independent estimates of $E_{\mathrm{L}}$. However, these slight decreases in errors $\left(\varepsilon_{L}\right)$ for independent land use emission estimates have been largely offset by the disagreement among independent estimates (Fig. 4). The combination of these factors has resulted in very little change in the overall error structure of $E_{\mathrm{L}}$ over the last 50 years (Table 1 ). Because $E_{\mathrm{L}}$ and $\varepsilon_{\mathrm{L}}$ have remained fairly constant over the last 5 decades the proportion of error contributed to global uncertainty in $\mathrm{C}$ uptake has remained at approximately 0.4 (Fig. 11).

\subsection{Changes in net global $\mathrm{C}$ uptake and the airborne fraction}

A clear and significant acceleration in net global C uptake has been observed from 1959 to 2010 , with net rates of annual $\Sigma N$ nearly doubling from $2.2 \pm 1.8 \mathrm{Pg} \mathrm{C} \mathrm{yr}^{-1}$ in 1959 to $4.3 \pm 1.6 \mathrm{Pg} \mathrm{C} \mathrm{yr}^{-1}$ in $2010( \pm 2 \sigma)$. This acceleration in $\Sigma N$ corresponds to a $0.5 \mathrm{Pg} \mathrm{C}$ decade $^{-1}$ increase in the amount of $\mathrm{C}$ taken up by Earth over the past 50 years (Fig. 7). Furthermore, this increasing trend in net global $\mathrm{C}$ uptake, as evidenced by progressively more negative $\Sigma N$ values, appears to be insensitive to whether land use emissions are included in our global $\mathrm{C}$ budget (Fig. 8a and b). For both emission scenarios with and without land use emissions, $\Sigma N$ trends were all negative. In fact, when $E_{\mathrm{L}}$ emissions are removed from our calculations of $\Sigma N$, we see that the trend in $\Sigma N$ actually increases from -0.05 to $-0.06 \mathrm{Pg} \mathrm{C} \mathrm{yr}^{-1}$ (see median values in Fig. 8a and b). Although a clear and significant increase in $\Sigma N$ is evident over the last 50 years, there is considerable decadal variability as well. We see that $\Sigma N$ increased 

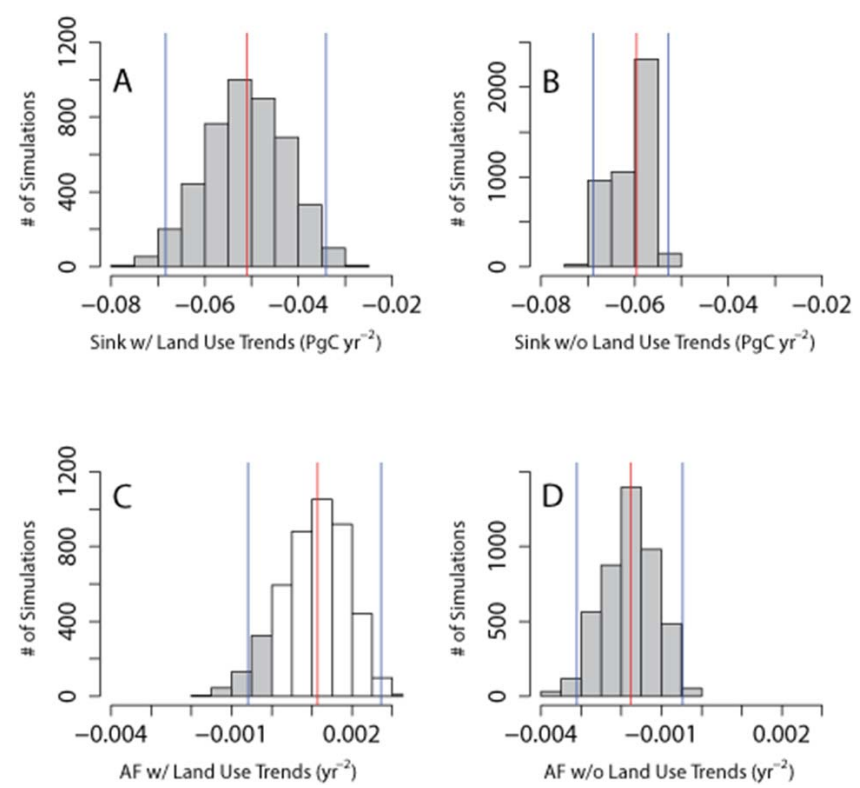

Figure 8. Trends in global carbon uptake. Plotted are the histograms of slopes fitted to 4500 simulations of net global carbon uptake, i.e., global sink $\Sigma N$ in (a) and (b) and the airborne fraction (AF) in panels $\mathbf{c}$ and $\mathbf{d}$. Also plotted are the slopes fitted to 4500 simulations without land use emissions included for $\Sigma N$ (b) and $\mathrm{AF}$ (c). Negative trend slopes (grey filled bars) of $\Sigma N$ indicate accelerating net global $\mathrm{C}$ uptake, whereas positive slopes (open bars) of AF indicate a decrease in relative $\mathrm{C}$ uptake efficiency. The median slope values are overlaid (red lines) for comparison with the $2 \sigma$ trend calculations (blue lines).

by $\sim 30 \%$ from the 1960 s to the 1970 s, but only a $\sim 5 \%$ increase in $\Sigma N$ was observed from the 1990s to the 2000s (Table 1). This suggests that the increase in global $\mathrm{C}$ uptake has not been a steady increase but can be characterized by periods of rapid acceleration and periods of slow or no acceleration (Table 1). The decadal means of the standard deviations of $\Sigma N$ have steadily gone down over the last 50 years, indicating that our ability to detect changes in global C uptake has improved (Table 1). However, this increased detection ability of $\Sigma N$ over time has been somewhat undermined by the recent uptick in global $\mathrm{C}$ uptake uncertainty over the last 10 years, due to increasing errors in fossil fuel emission estimates (Fig. 11). In contrast, the decadal standard deviation of the mean values of $\Sigma N$ has increased over the last 50 years, indicating an increase in the observed variability of global $\mathrm{C}$ uptake that appears to have peaked at $1.37 \mathrm{Pg} \mathrm{C} \mathrm{yr}^{-1}$ during the 1990s (Table 1).

The airborne fraction of atmospheric $\mathrm{CO}_{2}$ has only increased slightly over the last 5 decades, and this increase is not significant (Fig. 7). Furthermore, the airborne fraction appears to be highly sensitive to whether land use emissions are included in our emission scenario. For instance, mostly positive trends were observed in $\mathrm{AF}$ when both land use and fossil fuels were included in our emission scenario, indicat-

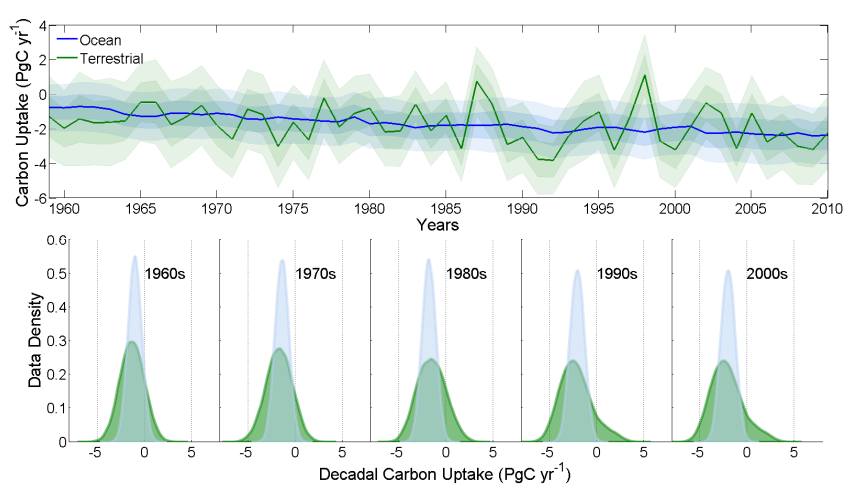

Figure 9. Trends in global carbon uptake by the land and ocean: both the land (green line) and ocean (blue line) show increasing carbon uptake over the last 50 years, as evidenced by increasingly negative uptake values (top panel); confidence intervals represent the $1 \sigma$ (dark transparent) and $2 \sigma$ (light transparent) distribution about the mean values for the land (green line) and the ocean (blue line). Kernel density functions for the distribution of uptake by the land (green) and ocean (blue) by decades (bottom panel) showing the increase in $\mathrm{C}$ uptake by decade but also the increase in variance for land C uptake. See Supplement, Table 2, for ocean and terrestrial C uptake values and their uncertainty.

ing a possible increase in $\mathrm{AF}$ and a possible decrease in relative global $\mathrm{C}$ uptake efficiency (Fig. 8c). However, if we consider the fossil-fuel-only scenario, we see that the sign of AF trends becomes almost exclusively negative, indicating a possible increase in relative global $\mathrm{C}$ uptake efficiency (Fig. 8d). Although no significant trend in AF was observed within the bounds of the uncertainty of our analysis, a considerable decrease in annual AF variance was observed over the 50-year record of observations (Fig. 7). The decadal mean of the standard deviations has gone down from 0.16 in the 1960 s to 0.03 in the 2000s; such a decrease indicates that our ability to detect changes in AF has increased by a factor of 4. Similar to our $\Sigma N$ statistics, the standard deviation of the decadal means in AF has climbed steadily until the 1990s, suggesting that variability in the global $\mathrm{C}$ cycle peaked in the 1990s and has remained strong.

\subsection{Changes in the partitioning of $\mathrm{C}$ uptake between the ocean and land}

Both land and ocean $\mathrm{C}$ uptake have increased over the last 50 years; however, variability in this $\mathrm{C}$ uptake is quite different for these two components of the global $\mathrm{C}$ cycle (Fig. 9). The median value of our 4500 simulated $N_{\mathrm{O}}$ trends was $-0.031 \mathrm{Pg} \mathrm{Cyr}^{-2}$, and $97 \%$ of these simulated trends were negative (4378/4500), providing strong evidence that ocean $\mathrm{C}$ uptake as simulated by ocean biogeochemical models has increased over the last 50 years. Similarly, the median value for our inferred trends of $N_{\mathrm{L}}$ was $-0.024 \mathrm{Pg} \mathrm{C} \mathrm{yr}^{-2}$, with $93 \%$ of our simulations showing negative $N_{\mathrm{L}}$ trends (4185/4500). Therefore, given the full range of errors con- 


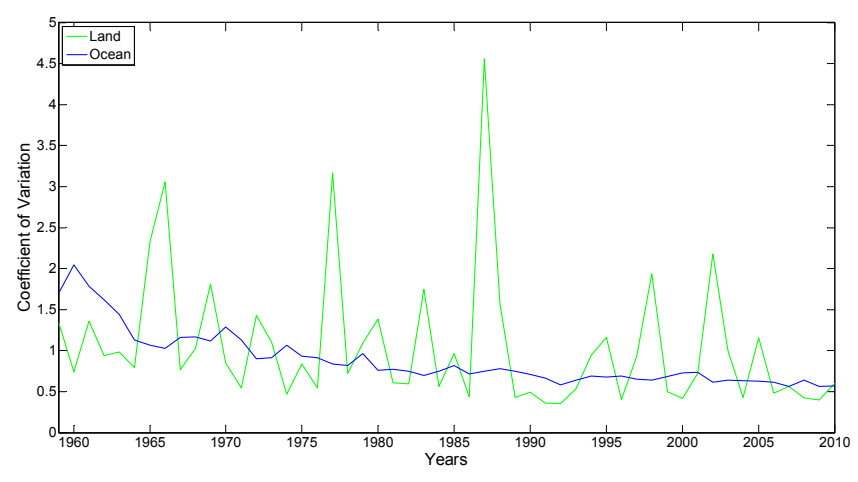

Figure 10. Coefficient of variation for net land and ocean C uptake for each year from 1959 to 2010. Coefficients of variation (CV) were calculated as the standard deviation/mean from each of our 4500 simulations of global annual $\mathrm{C}$ uptake. Values of CV for net land uptake (green) are compared with values of CV for net ocean uptake (blue). Absolute mean values were used to account for changes in sign of net land uptake that occurred over the 50-year period.

sidered in our analysis of atmospheric $\mathrm{CO}_{2}$ observations and emission estimates, we can say with an extremely high level of confidence that ocean $\mathrm{C}$ uptake has increased steadily and with a high level of confidence that land $\mathrm{C}$ uptake has increased but with greater variability over the last 50 years.

Although empirical evidence clearly shows that rates of ocean and land $\mathrm{C}$ uptake have increased, decadal variability of $N_{\mathrm{O}}$ and $N_{\mathrm{L}}$ show quite different patterns over the last 50 years. Rates of $N_{\mathrm{O}}$ have increased from $1.11 \pm 1.31 \mathrm{PgC} \mathrm{yr}^{-1}$ during the $1960 \mathrm{~s}$ to $2.21 \pm 1.39 \mathrm{PgC} \mathrm{yr}^{-1}$ during the 2000s (Table 1). Even though $N_{\mathrm{O}}$ rates have increased in every decade over which we have observationally constrained estimates, the percentage of increase in $N_{\mathrm{O}}$ has gone down from a $29 \%$ increase from the 1960 s to 1970 s to only an $8 \%$ increase from the 1990 s to 2000s. Over the past 5 decades, the mean of the standard deviations in $N_{\mathrm{O}}$ has remained fairly constant but increased slightly since 2000 , possibly due to a divergence in model predictions (Fig. 6). An alternative perspective is provided by the coefficient of variation of $N_{\mathrm{O}}$ which has gone down steadily over the last 50 years from $\sim 1.5$ to $\sim 0.6$, suggesting that our ability to detect changes in $N_{\mathrm{O}}$ has increased considerably (Fig. 10).

Much more variability in net land $\mathrm{C}$ uptake was observed in annual to decadal scales over the last 50 years. Rates of $N_{\mathrm{L}}$ have increased from $1.39 \pm 1.56 \mathrm{Pg} \mathrm{C} \mathrm{yr}^{-1}$ during the 1960 s to $2.46 \pm 1.43 \mathrm{Pg} \mathrm{C} \mathrm{yr}^{-1}$ during the 2000s (Table 1); however, considerable variability in $N_{\mathrm{L}}$ was also observed (Fig. 8). For instance, in $1987\left(N_{\mathrm{L}}=0.31 \pm 1.40 \mathrm{Pg} \mathrm{C} \mathrm{yr}^{-1}\right)$ and $1998\left(N_{\mathrm{L}}=0.82 \pm 1.58 \mathrm{Pg} \mathrm{Cyr}^{-1}\right)$ a net release of $\mathrm{CO}_{2}$ from the terrestrial biosphere to the atmosphere is inferred. Decadal variability in $N_{\mathrm{L}}$ also appears to be increasing, as evidenced by the increase in the standard deviation of the annual mean $N_{\mathrm{L}}$ values from $0.56 \mathrm{Pg} \mathrm{Cyr}^{-1}$ in the $1960 \mathrm{~s}$ to

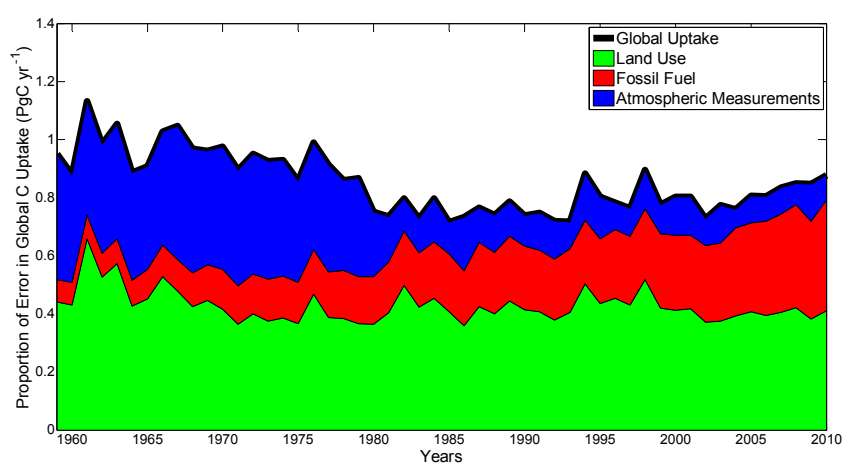

Figure 11. Proportion of error in terms contributing to the global carbon uptake. The total error in global $\mathrm{C}$ uptake is calculated as the square root sum of squared standard deviations for each term in the global budget (black line). The proportion of global $\mathrm{C}$ uptake uncertainty contributed from land use (green area) has remained fairly constant, the proportion of global $\mathrm{C}$ uptake uncertainty contributed from fossil fuels (red area) has risen in recent years, and the proportion of global $\mathrm{C}$ uptake uncertainty contributed from atmospheric $\mathrm{CO}_{2}$ measurements (blue area) has decreased.

$1.06 \mathrm{Pg} \mathrm{C} \mathrm{yr}^{-1}$ in the 2000s, with a peak in variance occurring during the decade of the 1990s (Table 1). Although net land $\mathrm{C}$ uptake appears to have become increasingly variable on decadal scales over the last 5 decades, our ability to detect changes in land $\mathrm{C}$ uptake and its interannual variability has improved. The mean of the standard deviations of $N_{\mathrm{L}}$ has decreased from $1.56 \mathrm{Pg} \mathrm{Cyr}^{-1}$ in the 1960 s to $1.43 \mathrm{Pg} \mathrm{C} \mathrm{yr}^{-1}$ in the 2000s, suggesting that our annual estimates of $N_{\mathrm{L}}$ are becoming more constrained over time (Table 1). This is also reflected in a slight decrease in the coefficient of variation of $N_{\mathrm{L}}$ from $\sim 1.0$ in the 1960 s to $\sim 0.5$ in the $2000 \mathrm{~s}$, albeit with much greater interannual differences (Fig. 10). Incidentally, both years that showed a net release of $\mathrm{CO}_{2}$ from the terrestrial biosphere to the atmosphere also showed relatively high coefficients of variation as the mean of $N_{\mathrm{L}}$ approached 0 in our simulations.

\section{Discussion}

\subsection{Atmospheric growth rate}

The stabilization of atmospheric $\mathrm{CO}_{2}$ concentrations is one of the greatest challenges to humanity; however, it is worth pointing out that in order to stabilize atmospheric $\mathrm{CO}_{2}$ concentrations, we must first stabilize the atmospheric $\mathrm{CO}_{2}$ growth rate. Unfortunately, there is no indication that the atmospheric $\mathrm{CO}_{2}$ growth rate is stabilizing; in fact, it has accelerated over the last 50 years $\left(0.05 \mathrm{Pg} \mathrm{Cyr}^{-2} ; p\right.$ value $=7.5 \times 10^{-7}$ ), such that every decade the growth rate has increased by $0.5 \mathrm{PgC}^{-1}$. Although the atmospheric $\mathrm{CO}_{2}$ growth rate has clearly accelerated it has not accelerated smoothly on decadal timescales. For instance, during the 
1980s the growth rate of atmospheric $\mathrm{CO}_{2}$ accelerated only slightly (0.04 $\left.\mathrm{Pg} \mathrm{Cyr}^{-2}\right)$, compared to the 1990 s when the atmospheric growth rate accelerated rapidly $\left(0.17 \mathrm{Pg} \mathrm{C} \mathrm{yr}^{-2}\right)$. While it has been suggested that these decadal changes in the growth rate of atmospheric $\mathrm{CO}_{2}$ are perhaps due to emission errors (Francey et al., 2013), our analysis suggests that this decadal variability is more likely due to variability in terrestrial C uptake consistent with previous analyses (Bousquet et al., 2000; Sarmiento et al., 2010).

Our ability to detect changes in atmospheric $\mathrm{CO}_{2}$ has increased considerably as additional sites have been added to the global monitoring network. The error in calculating $\frac{\hat{\mathrm{d} C}}{\mathrm{~d} t}$ has decreased by a factor of 4 from a mean value of $1.2 \mathrm{PgC}$ during the $1960 \mathrm{~s}$ to $0.3 \mathrm{Pg} \mathrm{C}$ during the 2000s. Even though the annual mean of $\frac{\hat{\mathrm{d} C}}{\mathrm{~d} t}$ has increased rapidly over the last 50 years, the standard deviation about this annual mean has decreased even faster, as evidenced by the annual coefficient of variation in $\frac{\hat{\mathrm{d} C}}{\mathrm{~d} t}$ that has gone down by a factor of 10 from 0.37 in the 1960 s to 0.04 in the 2000s. This increase in signal-to-noise ratio of $\frac{\hat{\mathrm{d} C}}{\mathrm{~d} t}$ once again clearly illustrates our increased ability to detect annual changes in atmospheric $\mathrm{CO}_{2}$ on the global scale. However, estimating global changes in $\frac{\hat{\mathrm{d} C}}{\mathrm{~d} t}$ from observations at an array of background sites is relatively easy compared to estimating regional changes in $\frac{\hat{\mathrm{d} C}}{\mathrm{~d} t}$ from continental sites even when an extensive network of frequent observations is available. For instance, Gourdji et al. (2012) found a $0.8 \mathrm{Pg} \mathrm{Cyr}^{-1}$ difference between two atmospheric inversion estimates of the $\mathrm{C}$ budget for North America depending on two different sets of boundary layer mixing ratios of $\mathrm{CO}_{2}$; their value is close to our $2 \sigma$ uncertainty of $1.2 \mathrm{Pg} \mathrm{C} \mathrm{yr}^{-1}$ for global C uptake for the year 2010 . Therefore, verifying potential changes in net $\mathrm{CO}_{2}$ fluxes on the regional to continental scale remains a challenge. Hopefully, advances in satellite observations, including the recently launched orbiting carbon observatory, in combination with careful surface measurements will make regional carbon accountability possible moving forward (Miller et al., 2014).

\subsection{Fossil fuel emissions}

At the inception of continuous atmospheric $\mathrm{CO}_{2}$ measurements in 1959, fossil fuel emissions constituted approximately $75 \%$ of the total emissions to the atmosphere; however, as fossil fuel emissions have increased, so has their relative contribution to the atmospheric burden of which fossil fuels now contribute $>90 \%$ (Table 1). As fossil fuel emissions have become the dominant driver of increasing atmospheric $\mathrm{CO}_{2}$ concentrations, absolute errors from fossil fuel emissions have also increased steadily, thus causing a slight increase in uncertainty of global $\mathrm{C}$ uptake in recent years (Fig. 11).

The greatest source of error in fossil fuel emission estimates is derived from national energy consumption statistics that can be as high as $20 \%$ of total emissions for some nations (Fig. 3) and may be even higher in some years due to the temporally correlated errors in emission estimates (Marland et al., 2009). Although the large errors in emission estimates have long been suspected, they have only recently been identified and quantified. For instance, by comparing provincial and national fossil fuel emission estimates in 2010, Guan et al. (2012) revealed a $1.4 \mathrm{Pg}$ discrepancy between national emission estimates that appear to be biased low and provincial emission estimates that appear to be biased high (Guan et al., 2012). This difference in fossil fuel emission estimates from China alone amounts to approximately $15 \%$ of the total global emissions for 2010. Similar analyses have not yet been conducted for other large emitting nations, but discrepancies probably exist in the reporting practices of many nations. If the absolute fossil fuel emission errors continue to grow, they will start to undermine our ability to estimate $\mathrm{C}$ uptake by the biosphere, especially on the regional scale (Francey et al., 2013). It is also noteworthy that some emission estimate errors may be simply accounting mistakes that do not require retroactively correcting previous estimates, and other errors may be improvements to protocols that may require retroactively correcting previous estimates, so our time-dependent error approach is more appropriate for the latter revisions to accounting protocols.

\subsection{Land use emissions}

Total emissions from land use change have gone down slightly over the last 2 decades and now rival the errors in fossil fuel emissions. As of 2010 the $2 \sigma$ error of $F_{\mathrm{F}}$ was approximately $\pm 0.59 \mathrm{PgC} \mathrm{yr}^{-1}$, whereas the total $E_{\mathrm{L}}$ was $0.76 \pm 0.98 \mathrm{Pg} \mathrm{Cyr}^{-1}$, clearly illustrating that $E_{\mathrm{L}}$ fluxes are contributing a smaller proportion to the overall atmospheric $\mathrm{CO}_{2}$ burden and that errors in estimating the $E_{\mathrm{L}}$ term remain quite large. This suggests that efforts to reduce the atmospheric $\mathrm{CO}_{2}$ growth rate or its concentration should focus primarily on reducing fossil fuel emissions and secondarily on changes in land use practices. So-called Reducing Emissions from Deforestation and Degradation (REDD) policy programs have been widely promoted; however, it is clear that fossil fuel emissions currently dwarf land use emissions. Therefore, current policies aimed at REDD programs may be misguided and their effectiveness maybe difficult to quantify (Matthews et al., 2014). Although C uptake is one of the most important ecosystem services currently provided by the terrestrial biosphere on the global scale, it is certainly not the only ecosystem service provided by the terrestrial biosphere.

Our analysis indicates the need to reduce the uncertainty in what constitutes land use emissions and how their errors are calculated. Although LULCC emission estimates from bookkeeping approaches and process model approaches are fairly comparable, discrepancies among these approaches may in fact be due to differences in the operational definition of what constitutes LULCC emissions (Houghton, 2013; Pongratz et 
al., 2014). In fact, LULCC emission estimates differ by as much as $30 \%$ suggesting that one third of the uncertainty in LULCC emissions is simply due to differences in terminology leading to differing treatments of deforestation and regrowth. Further, the errors in LULCC emission estimates are poorly constrained, with model simulations often not reporting estimate errors (Le Quéré et al., 2013) or bookkeeping methods often reporting relative errors. Land use emissions have gone down slightly from $\sim 1.5$ to $1.0 \mathrm{PgC} \mathrm{yr}^{-1}$ over the last 5 decades, so based on a relative $2 \sigma$ emission error of $50 \%$, one would conclude that absolute errors have also gone down from 0.75 to $0.50 \mathrm{Pg} \mathrm{C} \mathrm{yr}^{-1}$. However, based on the discrepancies among approaches it is clear that absolute errors have probably remained fairly constant over the last 5 decades (Fig. 4). Discrepancies among the different operational definitions of land use emissions and their impacts on the global $\mathrm{C}$ budget have been identified previously and methodological frameworks have been proposed for reconciling these different operational definitions and their estimates (Gasser and Ciais, 2013).

\subsection{Changes in land and ocean $\mathrm{C}$ uptake and their implications}

It is clear from our analysis that both the land and ocean biosphere continue to provide a tremendous climatic benefit by absorbing more than $50 \%$ of the total $\mathrm{CO}_{2}$ that has been emitted to the atmosphere over the last 50 years. According to our estimates, net global $\mathrm{C}$ uptake (i.e., $\Sigma N$ ) has nearly doubled over the last 50 years. While some evidence suggests that terrestrial $\mathrm{C}$ uptake may be waning in the Southern Hemisphere tropics (Zhao and Running, 2010) due to water stress and that the $\mathrm{C}$ uptake in the Southern Ocean might be reduced by increased surface winds (Le Quéré et al., 2007), our analysis indicates that these potential regional declines in both terrestrial and ocean $\mathrm{C}$ uptake are more than compensated for by increased $\mathrm{C}$ uptake elsewhere in the biosphere. At the same time our ability to detect changes in $\Sigma N$ has increased (Fig. 7), as evidenced by the decrease of the mean of the standard deviations by decade (Table 1). This reduced uncertainty in our ability to quantify $\Sigma N$ is mainly due to the reduced error in our estimates of the atmospheric growth rate due to the addition of sites to the global observing network (Fig. 11).

Another important diagnostic of how the global $\mathrm{C}$ cycle may be responding to concomitant changes in atmospheric $\mathrm{CO}_{2}$ and climate is the airborne fraction (i.e., $\mathrm{AF}$ ), which provides a useful estimate of possible changes in $C$ uptake efficiency by the biosphere. A possible increase in AF over the last 5 decades has been identified (Canadell et al., 2007) and attributed to a decrease in the efficiency with which $\mathrm{C}$ is being removed from the atmosphere by land and ocean sinks (Le Quéré et al., 2009). Our analysis suggests that there is considerable uncertainty with respect to possible trends in AF: the sign of the AF trend is slightly positive when includ- ing both fossil fuels and land use in our emission scenarios but the trend becomes negative if we do not consider land use in our emission scenarios. This result is consistent with Knorr (2009), who found that any apparent trend in AF was not statistically distinguishable from 0 , suggesting that there is too much uncertainty in the AF calculation to determine whether a trend is evident over the last 5 decades. It should also be noted that previous analyses were only able to identify a possible trend in AF after removing interannual variability in the atmospheric growth rate due to volcanic activity and El Niño, making the interpretation of any changes in the unitless relative AF even more difficult. Furthermore, it has been demonstrated from model simulations that changes in $\mathrm{AF}$ are more likely to be sensitive to rapid changes in fossil fuel emissions than C uptake efficiency (Gloor et al., 2010). However, it is important to note that the error associated with calculating AF appears to have gone down, which may make $\mathrm{AF}$ a more sensitive diagnostic of $\mathrm{C}$ cycle changes in the $\mathrm{fu}-$ ture.

The net exchange of carbon between the terrestrial biosphere and the atmosphere is challenging to estimate directly and can only be inferred; however, more tightly constrained estimates of the atmospheric $\mathrm{CO}_{2}$ growth rate have greatly reduced the error associated with the inferred residual $\mathrm{C}$ sink. As net global C uptake uncertainty has diminished (Fig. 11), so has uncertainty in our calculation of net land $\mathrm{C}$ uptake (i.e., $N_{\mathrm{L}}$ ). Indeed our estimates of $N_{\mathrm{L}}$ show an overall decrease in the mean of the standard deviation over the last 5 decades, which indicates that once again our ability to detect changes in $N_{\mathrm{L}}$ has improved in recent years (Table 1). While our estimates of changes in terrestrial $\mathrm{C}$ uptake are largely inferred as a byproduct ocean biogeochemical models, more recently derived independent observationally based estimates of ocean C uptake (Khatiwala et al., 2009; Majkut et al., 2014) will allow for more observational constraints on the largely inferred residual land $\mathrm{C}$ sink.

It is clearly evident that net land $\mathrm{C}$ uptake has increased over the last 50 years (Fig. 9). Independent analyses from observations and models corroborate our findings that the absolute value of $N_{\mathrm{L}}$ has increased over the last 5 decades. A synthesis of data on $\mathrm{C}$ budgets of the world's forests concluded that terrestrial $\mathrm{C}$ uptake has remained strong and fairly constant from 1990 through the 2000s (Pan et al., 2011). In their synthesis, Pan et al. (2011) conclude that $N_{\mathrm{L}}$ was $2.5 \pm 0.4 \mathrm{Pg} \mathrm{C} \mathrm{yr}^{-1}$ during the $1990 \mathrm{~s}$ and only decreased slightly to $2.3 \pm 0.5 \mathrm{Pg} \mathrm{Cyr}^{-1}$ from 2000 to 2007 . These estimates are fairly close to our estimates, although our estimates indicate a slight increase in $N_{\mathrm{L}}$ from the $1990 \mathrm{~s}$ $\left(2.35 \pm 1.5 \mathrm{PgC} \mathrm{yr}^{-1}\right)$ to the $2000 \mathrm{~s}\left(2.46 \pm 1.4 \mathrm{PgC} \mathrm{yr}^{-1}\right)$, but with greater uncertainty (Table 1 ). It should be noted that there is considerable decadal variability in $N_{\mathrm{L}}$ and that the conclusions from Pan et al. (2011) might have been completely different had they compared the 1970s to the 1980s, over which time the amount of $\mathrm{C}$ uptake by the terrestrial biosphere actually decreased, as evidenced by an increase in 
$N_{\mathrm{L}}$ (Table 1.). Increases in terrestrial C uptake are also evident in estimates from dynamic vegetation models and atmospheric inversion studies, which both show terrestrial C uptake increasing from 1980 and peaking in 2011 (Poulter et al., 2014).

While net terrestrial $\mathrm{C}$ uptake has increased over the last 5 decades, the variability in net land $\mathrm{C}$ uptake appears to have increased as well. In fact, the standard deviation of the means in decadal $\mathrm{C}$ uptake by the terrestrial biosphere increased by almost a factor of 3 from the 1960s through the 1990s, and since 2000 the variability in net terrestrial $\mathrm{C}$ uptake has gone down slightly (Table 1). Although several well-documented stochastic events occurred during the latter half of the observational record, including two strong El Niño events in 1987 and 1997 as well as the eruption of Mt. Pinatubo in 1991, there remains an apparent increase in the variability of net $\mathrm{C}$ uptake by the terrestrial biosphere. More recently, semiarid ecosystems have been identified as regions of increased photosynthetic activity and potentially enhanced C uptake (Donohue et al., 2013; Poulter et al., 2014); however, it should be noted that these ecosystems are often the most vulnerable to carbon loss due to disturbance (Reichstein et al., 2013), and thus increased $\mathrm{C}$ uptake during favorable climate conditions may be followed by increased $\mathrm{C}$ loss during extreme climate events, ultimately leading to the increased variance in net terrestrial $\mathrm{C}$ uptake observed in our analysis. It is also worth pointing out that in some instances when multiple disturbances of sufficient magnitude force the carbon system in the same direction, their effect can be detected in the atmosphere. For instance, one of the most severe El Niño events occurred in 1997 and this event was associated with widespread tropical drought that was thought to reduce photosynthesis on a global scale (Nemani et al., 2003). However, the impact of this random climatic event was greatly exacerbated by land use practices in Southeast Asia that promoted the draining of peatlands, which subsequently burned during the El Niño event (Ballhorn et al., 2009), thus providing evidence of how compound disturbances to the terrestrial C cycle can actually be detected in the atmosphere. It remains to be seen whether this variability is simply the slow resilience of the biosphere to global perturbations or whether this increased variance indicates a potential regime shift in the terrestrial C cycle (Reichstein et al., 2013).

Based on our error analysis across a range of ocean biogeochemical models, there is no clear indication that ocean $\mathrm{C}$ uptake has diminished over the last 50 years. Although ocean $\mathrm{C}$ uptake appears to have accelerated steadily by 0.2 and $0.3 \mathrm{Pg} \mathrm{C} \mathrm{yr}^{-1}$ decade $^{-1}$ from the 1960 s to the 1990 s, ocean $\mathrm{C}$ uptake may have decreased slightly to $0.14 \mathrm{Pg} \mathrm{C} \mathrm{yr}^{-1}$ over the last decade. However, at the same time the mean of the annual standard deviations also increased over the last decade, suggesting less agreement among ocean models and making it more difficult to detect the possible early stages of ocean $\mathrm{CO}_{2}$ saturation. Much of the discussion regarding possible $\mathrm{CO}_{2}$ saturation of the oceans has focused on the Southern Ocean because it contributes such a large portion $\left(0.4 \mathrm{Pg} \mathrm{Cyr}^{-1}\right)$ to the recent net global annual ocean $\mathrm{C}$ uptake of $\sim 2.0 \mathrm{Pg} \mathrm{Cyr}^{-1}$ (Le Quéré et al., 2007; Lovenduski et al., 2007). Unfortunately, this is a region of the Earth for which atmospheric $\mathrm{CO}_{2}$ measurements and oceanic $p \mathrm{CO}_{2}$ measurements are fairly scarce. In fact, estimates between ocean biogeochemical models $\left(0.42 \pm 0.07 \mathrm{Pg} \mathrm{C} \mathrm{yr}^{-1}\right)$ and observational constraints $\left(0.27 \pm 0.13 \mathrm{Pg} \mathrm{C} \mathrm{yr}^{-1}\right)$ for the Southern Ocean are not even in statistical agreement (Lenton et al., 2013), suggesting that possible $\mathrm{CO}_{2}$ saturation of the Southern Ocean would be extremely difficult to detect if it were in fact occurring, given the current configuration of the global $\mathrm{C}$ observation network. It should also be noted that factors influencing the kinetics of air-sea gas exchange and how they are incorporated into these ocean biogeochemical models may have a large impact on global estimates of $N_{\mathrm{O}}$. For instance, the gas transfer velocity term used in calculating $N_{\mathrm{O}}$ incorporates a solubility function and wind speed function, neither of which are linear functions (Wanninkhof et al., 2013). Although these functions have been optimized based on empirical studies, it is not known how much regional variability there is in these functions and whether it is valid to apply a universal air-sea gas exchange parameterization to all ocean basins.

Although the climate benefit conferred by increased land and ocean $\mathrm{C}$ uptake is irrefutable, this climate benefit may come at some expense, namely, of the biosphere providing other vital ecosystem services. The greatest and most easily quantified impact of increased $\mathrm{C}$ uptake has been on the oceans through decreases in $\mathrm{pH}$. It has been estimated that the $\mathrm{pH}$ of the ocean has decreased by 0.1 over the last 50 years, which is equivalent to a $20 \%$ increase in hydrogen ion concentration (Doney et al., 2009) . This increase in ocean acidity is particularly harmful for calcareous organisms, especially those with shells formed from aragonite, such as corals that form the base of many tropical marine ecoystems and pteropods that form the base of many pelagic marine ecosystems (Doney et al., 2009). Although some studies suggest that increased dissolved inorganic carbon in the water column may stimulate the biologic pump and thus primary productivity in the ocean (Riebesell et al., 2007), the direct impacts of acidification on calcareous organisms and the indirect impacts of increasing sea surface temperatures are thought to have a net negative effect on ocean productivity (Doney et al., 2009).

In contrast, the direct impacts of rising $\mathrm{CO}_{2}$ on the terrestrial biosphere may be both positive and negative. For instance, the fertilizing effect of increasing atmospheric $\mathrm{CO}_{2}$ on photosynthesis in terrestrial plants is well documented (Ainsworth and Long, 2005), leading to potential increases in water use efficiency as terrestrial plants become more frugal with water losses through transpiration (Keenan et al., 2013). Although the detrimental effects of increasing atmospheric $\mathrm{CO}_{2}$ on the terrestrial biosphere are not as obvious, they may be just as insidious. For instance, increasing atmo- 
spheric $\mathrm{CO}_{2}$ has been implicated in the accelerated weathering of bedrock (Andrews and Schlesinger, 2001), which can release both harmful and beneficial elements from Earth's lithosphere into terrestrial ecosystems (Mast et al., 2011). It has also been suggested that $\mathrm{CO}_{2}$ fertilization may differentially affect the growth of plant species, with faster growth in epiphytes such as lianas leading to tree mortality (Phillips et al., 2002). While the detrimental impacts of increased atmospheric $\mathrm{CO}_{2}$ on terrestrial ecosystems are more challenging to identify because $\mathrm{CO}_{2}$ is well mixed on annual timescales, there is no ecosystem on Earth that has not been impacted by increasing $\mathrm{CO}_{2}$ concentration, and more detrimental impacts will undoubtedly be identified in the future.

\section{Conclusions}

As scientists it is no longer sufficient to simply arrive at an estimate; we must bound our estimates with some level of confidence. This is particularly important when investigating something as important as the global $\mathrm{C}$ cycle and the climate sensitivity of carbon sinks that continue to take up atmospheric $\mathrm{CO}_{2}$. Because the topic of carbon-climate feedbacks is critical for both political and social decisions on the global scale, we must provide the public with the best estimates of important terms in the global carbon budget and their respective uncertainties. The uncertainty that arises from measurement, analytical, and estimate errors is important because it provides scientists and policy makers alike with a metric by which to weight the information provided when it is incorporated into their decision making framework. For instance, the effectiveness of policies targeted at fossil fuel emissions, with their relatively high rates and low errors, may be easier to verify than the effectiveness of policies targeted at land use emissions, which are fraught with uncertainty. In fact, errors associated with fossil fuel emissions are now comparable to total emissions from changes in LULCC (Table 1). Here, we have created a framework by which estimate errors can be explicitly incorporated into the global $\mathrm{C}$ budget, allowing for the calculation of uncertainty in global $\mathrm{C}$ uptake. We have identified some major sources of error and their important spatial and temporal components; however, we acknowledge that latent sources of error do exist and thus can be incorporated into the flexible framework that we have created. Despite the many sources of error that we have identified in estimating terms in the global $\mathrm{C}$ budget, we conclude with an extremely high level of confidence that ocean $\mathrm{C}$ uptake has increased over the past 50 years and with a high level of confidence that land $\mathrm{C}$ uptake has also increased.

\section{The Supplement related to this article is available online at doi:10.5194/bg-12-2565-2015-supplement.}

Acknowledgements. This research was supported by grants from NSF and NRC to A. P. Ballantyne. This work would not have been possible without the continuous atmospheric sampling efforts of dozens of volunteer scientists from around the world and careful measurements by researchers at NOAA ESRL. We would also like to thank Gregg Marland, Glen Peters, and one anonymous reviewer, as well as students in the Emerging Topics in Ecosystem Science seminar at the University of Montana for helpful feedback.

Edited by: T. Keenan

\section{References}

Ainsworth, E. A. and Long, S. P.: What have we learned from 15 years of free-air $\mathrm{CO}_{2}$ enrichment (FACE)?, A meta-analytic review of the responses of photosynthesis, canopy properties and plant production to rising $\mathrm{CO}_{2}$, New Phytol., 165, 351-372, 2005.

Andres, R. J., Boden, T. A., Bréon, F.-M., Ciais, P., Davis, S., Erickson, D., Gregg, J. S., Jacobson, A., Marland, G., Miller, J., Oda, T., Olivier, J. G. J., Raupach, M. R., Rayner, P., and Treanton, K.: A synthesis of carbon dioxide emissions from fossil-fuel combustion, Biogeosciences, 9, 1845-1871, doi:10.5194/bg-9-18452012, 2012.

Andres, R., Boden, T., and Higdon, D.: A new evaluation of the uncertainty associated with CDIAC estimates of fossil fuel carbon dioxide emission, Tellus, 66, 23616, doi:10.3402/tellusb.v66.23616, 2014.

Andrews, J. A. and Schlesinger, W. H.: Soil $\mathrm{CO}_{2}$ dynamics, acidification, and chemical weathering in a temperate forest with experimental $\mathrm{CO}_{2}$ enrichment, Global Biogeochem. Cy., 15, 149-162, 2001.

Bakker, D., Hankin, S., Olsen, A., Pfeil, B., Smith, K., Alin, S., Cosca, C., Hales, B., Harasawa, S., and Kozyr, A.: An update to the Surface Ocean $\mathrm{CO}_{2}$ Atlas (SOCAT version 2), Earth Syst. Sci. Data, 6, 69-90, 2014, http://www.earth-syst-sci-data.net/6/69/2014/.

Ballantyne, A., Alden, C., Miller, J., Tans, P., and White, J.: Increase in observed net carbon dioxide uptake by land and oceans during the past 50 years, Nature, 488, 70-72, 2012

Ballhorn, U., Siegert, F., Mason, M., and Limin, S.: Derivation of burn scar depths and estimation of carbon emissions with LIDAR in Indonesian peatlands, Proc. Natl. Acad. Sci., 106, 21213 21218, 2009.

Boden, T. A., Marland, G., and Andres, R. J.: Global, regional, and national fossil-fuel $\mathrm{CO}_{2}$ emissions, Carbon Dioxide Information Analysis Center, Oak Ridge National Laboratory, US Department of Energy, Oak Ridge, Tenn., USA, doi:10.3334/CDIAC/00001_V2012, 2009.

Bousquet, P., Peylin, P., Ciais, P., Le Quéré, C., Friedlingstein, P., and Tans, P. P.: Regional changes in carbon dioxide fluxes of land and oceans since 1980, Science, 290, 1342-1346, 2000.

Canadell, J. G., Le Quéré, C., Raupach, M. R., Field, C. B., Buitenhuis, E. T., Ciais, P., Conway, T. J., Gillett, N. P., Houghton, R., and Marland, G.: Contributions to accelerating atmospheric $\mathrm{CO}_{2}$ growth from economic activity, carbon intensity, and efficiency of natural sinks, Proc. Natl. Acad. Sci., 104, 18866-18870, 2007. 
Canadell, J. G., Ciais, P., Gurney, K., Le Quéré, C., Piao, S., Raupach, M. R., and Sabine, C. L.: An international effort to quantify regional carbon fluxes, Eos, Transactions American Geophysical Union, 92, 81-82, 2011.

Conway, T. J., Tans, P. P., Waterman, L. S., Thoning, K. W., Kitzis, D. R., Masarie, K. A., and Zhang, N.: Evidence for interannual variability of the carbon cycle from the National Oceanic and Atmospheric Administration/Climate Monitoring and Diagnostics Laboratory global air sampling network, J. Geophys. Res. Atmos. (1984-2012), 99, 22831-22855, 1994.

Dai, M., Cao, Z., Guo, X., Zhai, W., Liu, Z., Yin, Z., Xu, Y., Gan, J., Hu, J., and Du, C.: Why are some marginal seas sources of atmospheric $\mathrm{CO}_{2}$ ?, Geophys. Res. Lett., 40, 2154-2158, 2013.

DeFries, R., Field, C., Fung, I., Collatz, G., and Bounoua, L.: Combining satellite data and biogeochemical models to estimate global effects of human-induced land cover change on carbon emissions and primary productivity, Global Biogeochem. Cy., 13, 803-815, 1999.

Doney, S. C., Fabry, V. J., Feely, R. A., and Kleypas, J. A.: Ocean acidification: the other $\mathrm{CO}_{2}$ problem, Mar. Sci., 1, 169-192, 2009.

Donohue, R. J., Roderick, M. L., McVicar, T. R., and Farquhar, G. D.: Impact of $\mathrm{CO}_{2}$ fertilization on maximum foliage cover across the globe's warm, arid environments, Geophys. Res. Lett., 40, 3031-3035, 2013.

FAO: Global Forest Resources Assessment 2010, Rome, FAO Forestry paper, 2010.

Francey, R. J., Trudinger, C. M., van der Schoot, M., Law, R. M., Krummel, P. B., Langenfelds, R. L., Steele, L. P., Allison, C. E., Stavert, A. R., and Andres, R. J.: Atmospheric verification of anthropogenic $\mathrm{CO}_{2}$ emission trends, Nat. Clim. Change, 3, 520524, 2013

Friedlingstein, P., Houghton, R., Marland, G., Hackler, J., Boden, T. A., Conway, T., Canadell, J., Raupach, M., Ciais, P., and Le Quere, C.: Update on $\mathrm{CO}_{2}$ emissions, Nature Geosci., 3, 811$812,2010$.

Gasser, T. and Ciais, P.: A theoretical framework for the net landto-atmosphere $\mathrm{CO}_{2}$ flux and its implications in the definition of "emissions from land-use change", Earth Syst. Dynam., 4, 171186, doi:10.5194/esd-4-171-2013, 2013.

Gloor, M., Sarmiento, J. L., and Gruber, N.: What can be learned about carbon cycle climate feedbacks from the $\mathrm{CO}_{2}$ airborne fraction?, Atmos. Chem. Phys., 10, 7739-7751, doi:10.5194/acp10-7739-2010, 2010.

Gourdji, S. M., Mueller, K. L., Yadav, V., Huntzinger, D. N., Andrews, A. E., Trudeau, M., Petron, G., Nehrkorn, T., Eluszkiewicz, J., Henderson, J., Wen, D., Lin, J., Fischer, M., Sweeney, C., and Michalak, A. M.: North American $\mathrm{CO}_{2}$ exchange: inter-comparison of modeled estimates with results from a fine-scale atmospheric inversion, Biogeosciences, 9, 457-475, doi:10.5194/bg-9-457-2012, 2012.

Guan, D., Liu, Z., Geng, Y., Lindner, S., and Hubacek, K.: The gigatonne gap in China's carbon dioxide inventories, Nat. Clim. Change, 2, 672-675, 2012.

Hansen, M., Potapov, P., Moore, R., Hancher, M., Turubanova, S., Tyukavina, A., Thau, D., Stehman, S., Goetz, S., and Loveland, T.: High-resolution global maps of 21 st-century forest cover change, Science, 342, 850-853, 2013.
Houghton, R., Hobbie, J., Melillo, J. M., Moore, B., Peterson, B., Shaver, G., and Woodwell, G.: Changes in the Carbon Content of Terrestrial Biota and Soils between 1860 and 1980: A Net Release of $\mathrm{CO}_{2}$ to the Atmosphere, Ecol. Monogr., 53, 235-262, 1983.

Houghton, R. A.: Land?use change and the carbon cycle, Global change biology, 1, 275-287, 1995.

Houghton, R. A.: Keeping management effects separate from environmental effects in terrestrial carbon accounting, Glob. Change Biol., 19, 2609-2612, 2013.

Houghton, R. A., House, J. I., Pongratz, J., van der Werf, G. R., DeFries, R. S., Hansen, M. C., Le Quéré, C., and Ramankutty, N.: Carbon emissions from land use and land-cover change, Biogeosciences, 9, 5125-5142, doi:10.5194/bg-9-5125-2012, 2012.

Ishidoya, S., Aoki, S., Goto, D., Nakazawa, T., Taguchi, S., and Patra, P. K.: Time and space variations of the $\mathrm{O}_{2} / \mathrm{N}_{2}$ ratio in the troposphere over Japan and estimation of the global $\mathrm{CO}_{2}$ budget for the period 2000-2010, Tellus B, 64, 18964, doi:10.3402/tellusb.v64i0.18964, 2012.

Jain, A. K., Meiyappan, P., Song, Y., and House, J. I.: $\mathrm{CO}_{2}$ emissions from land-use change affected more by nitrogen cycle, than by the choice of land-cover data, Glob. Change Biol., 19, 2893 2906, 2013.

Keeling, C., Whorf, T., Wahlen, M., and Plicht, J. v. d.: Interannual extremes in the rate of rise of atmospheric carbon dioxide since 1980, Nature, 375, 666-670, 1995.

Keeling, C. D.: The concentration and isotopic abundances of carbon dioxide in the atmosphere, Tellus, 12, 200-203, 1960.

Keeling, C. D., Piper, S. C., Bacastow, R. B., Wahlen, M., Whorf, T. P., Heimann, M., and Meijer, H. A.: Atmospheric $\mathrm{CO}_{2}$ and ${ }^{13} \mathrm{CO}_{2}$ exchange with the terrestrial biosphere and oceans from 1978-2000: observations and carbon cycle implications, in: A history of atmospheric $\mathrm{CO}_{2}$ and its effects on plants, animals, and ecosystems, Springer, 83-113, 2005.

Keeling, C. D., Piper, S. C., Whorf, T. P., and Keeling, R. F.: Evolution of natural and anthropogenic fluxes of atmospheric $\mathrm{CO}_{2}$ from 1957-2003, Tellus B, 63, 1-22, 2011.

Keenan, T. F., Hollinger, D. Y., Bohrer, G., Dragoni, D., Munger, J. W., Schmid, H. P., and Richardson, A. D.: Increase in forest water-use efficiency as atmospheric carbon dioxide concentrations rise, Nature, 499, 324-327, 2013.

Khatiwala, S., Primeau, F., and Hall, T.: Reconstruction of the history of anthropogenic $\mathrm{CO}_{2}$ concentrations in the ocean, Nature, 462, 346-349, 2009.

Knorr, W.: Is the airborne fraction of anthropogenic $\mathrm{CO}_{2}$ emissions increasing?, Geophys. Res. Lett., 36, L21710, doi:10.1029/2009GL040613, 2009.

Landschützer, P., Gruber, N., Bakker, D. C. E., Schuster, U., Nakaoka, S., Payne, M. R., Sasse, T. P., and Zeng, J.: A neural network-based estimate of the seasonal to inter-annual variability of the Atlantic Ocean carbon sink, Biogeosciences, 10, 7793-7815, doi:10.5194/bg-10-7793-2013, 2013.

Lenton, A., Tilbrook, B., Law, R. M., Bakker, D., Doney, S. C., Gruber, N., Ishii, M., Hoppema, M., Lovenduski, N. S., Matear, R. J., McNeil, B. I., Metzl, N., Mikaloff Fletcher, S. E., Monteiro, P. M. S., Rödenbeck, C., Sweeney, C., and Takahashi, T.: Seaair $\mathrm{CO}_{2}$ fluxes in the Southern Ocean for the period 1990-2009, Biogeosciences, 10, 4037-4054, doi:10.5194/bg-10-4037-2013, 2013. 
Le Quéré, C., Rödenbeck, C., Buitenhuis, E. T., Conway, T. J., Langenfelds, R., Gomez, A., Labuschagne, C., Ramonet, M., Nakazawa, T., Metzl, N., Gillett, N., and Heimann, M.: Saturation of the Southern Ocean $\mathrm{CO}_{2}$ Sink Due to Recent Climate Change, Science, 316, 1735-1738, 2007.

Le Quéré, C., Raupach, M. R., Canadell, J. G., Marland, G., Bopp, L., Ciais, P., Conway, T. J., Doney, S. C., Feely, R. A., and Foster, P.: Trends in the sources and sinks of carbon dioxide, Nat. Geosci., 2, 831-836, 2009.

Le Quéré, C., Takahashi, T., Buitenhuis, E. T., Rödenbeck, C., and Sutherland, S. C.: Impact of climate change and variability on the global oceanic sink of $\mathrm{CO}_{2}$, Global Biogeochem. Cy., 24, GB4007, doi:10.1029/2009GB003599, 2010.

Le Quéré, C., Andres, R. J., Boden, T., Conway, T., Houghton, R. A., House, J. I., Marland, G., Peters, G. P., van der Werf, G. R., Ahlström, A., Andrew, R. M., Bopp, L., Canadell, J. G., Ciais, P., Doney, S. C., Enright, C., Friedlingstein, P., Huntingford, C., Jain, A. K., Jourdain, C., Kato, E., Keeling, R. F., Klein Goldewijk, K., Levis, S., Levy, P., Lomas, M., Poulter, B., Raupach, M. R., Schwinger, J., Sitch, S., Stocker, B. D., Viovy, N., Zaehle, S., and Zeng, N.: The global carbon budget 1959-2011, Earth Syst. Sci. Data, 5, 165-185, doi:10.5194/essd-5-165-2013, 2013.

Li, Z., Adamec, D., Takahashi, T., and Sutherland, S. C.: Global autocorrelation scales of the partial pressure of oceanic $\mathrm{CO}_{2}$, J. Geophys. Res. Oc. (1978-2012), 110, C08002, doi:10.1029/2004JC002723, 2005.

Lovenduski, N. S., Gruber, N., Doney, S. C., and Lima, I. D.: Enhanced $\mathrm{CO}_{2}$ outgassing in the Southern Ocean from a positive phase of the Southern Annular Mode, Global Biogeochem. Cy., 21, GB2026, doi:10.1029/2006GB002900, 2007.

Majkut, J. D., Sarmiento, J., and Rodgers, K.: A growing oceanic carbon uptake: results from an inversion study of surface $p \mathrm{CO}_{2}$ data, Global Biogeochem. Cy., 28, 335-351, 2014.

Manning, A. C., and Keeling, R. F.: Global oceanic and land biotic carbon sinks from the Scripps atmospheric oxygen flask sampling network, Tellus B, 58, 95-116, 2006.

Marland, G., Hamal, K., and Jonas, M.: How Uncertain Are Estimates of $\mathrm{CO}_{2}$ Emissions?, J. Indust. Ecol., 13, 4-7, 2009.

Masarie, K. A. and Tans, P. P.: Extension and integration of atmospheric carbon dioxide data into a globally consistent measurement record, J. Geophys. Res. Atmos. (1984-2012), 100, $11593-$ 11610, 1995.

Mast, M. A., Turk, J. T., Clow, D. W., and Campbell, D. H.: Response of lake chemistry to changes in atmospheric deposition and climate in three high-elevation wilderness areas of Colorado, Biogeochemistry, 103, 27-43, 2011.

Matthews, R. B., van Noordwijk, M., Lambin, E., Meyfroidt, P., Gupta, J., Verchot, L., Hergoualc'h, K., and Veldkamp, E.: Implementing REDD+ (Reducing Emissions from Deforestation and Degradation): evidence on governance, evaluation and impacts from the REDD-ALERT project, Mitigat. Adaptat. Strateg. Glob. Change, 19, 907-925, 2014.

Miller, J. B., Tans, P. P., and Gloor, M.: Steps for success of OCO-2, Nat. Geosci., 7, 691-691, 2014.

Nemani, R. R., Keeling, C. D., Hashimoto, H., Jolly, W. M., Piper, S. C., Tucker, C. J., Myneni, R. B., and Running, S. W.: Climatedriven increases in global terrestrial net primary production from 1982 to 1999 , Science, 300, 1560-1563, 2003.
Pan, Y., Birdsey, R. A., Fang, J., Houghton, R., Kauppi, P. E., Kurz, W. A., Phillips, O. L., Shvidenko, A., Lewis, S. L., and Canadell, J. G.: A large and persistent carbon sink in the world's forests, Science, 333, 988-993, 2011.

Phillips, O. L., Martínez, R. V., Arroyo, L., Baker, T. R., Killeen, T., Lewis, S. L., Malhi, Y., Mendoza, A. M., Neill, D., and Vargas, P N.: Increasing dominance of large lianas in Amazonian forests, Nature, 418, 770-774, 2002.

Pongratz, J., Reick, C. H., Houghton, R. A., and House, J. I.: Terminology as a key uncertainty in net land use and land cover change carbon flux estimates, Earth Syst. Dynam., 5, 177-195, doi:10.5194/esd-5-177-2014, 2014.

Poulter, B., Frank, D., Ciais, P., Myneni, R. B., Andela, N., Bi, J., Broquet, G., Canadell, J. G., Chevallier, F., and Liu, Y. Y.: Contribution of semi-arid ecosystems to interannual variability of the global carbon cycle, Nature, 509, 600-603, 2014.

Raupach, M., Le Quéré, C., Peters, G., and Canadell, J.: Anthropogenic $\mathrm{CO}_{2}$ emissions, Nat. Clim. Change, 3, 603-604, 2013.

Reichstein, M., Bahn, M., Ciais, P., Frank, D., Mahecha, M. D., Seneviratne, S. I., Zscheischler, J., Beer, C., Buchmann, N., and Frank, D. C.: Climate extremes and the carbon cycle, Nature, 500, 287-295, 2013.

Riebesell, U., Schulz, K. G., Bellerby, R., Botros, M., Fritsche, P., Meyerhöfer, M., Neill, C., Nondal, G., Oschlies, A., and Wohlers, J.: Enhanced biological carbon consumption in a high $\mathrm{CO}_{2}$ ocean, Nature, 450, 545-548, 2007.

Rödenbeck, C., Keeling, R., Bakker, D., Metzl, N., Olsen, A., Sabine, C., and Heimann, M.: Global surface-ocean $p \mathrm{CO}_{2}$ and sea-air $\mathrm{CO}_{2}$ flux variability from an observation-driven ocean mixed-layer scheme, 9, 193-216, 2013.

Sarmiento, J. L., Gloor, M., Gruber, N., Beaulieu, C., Jacobson, A. R., Mikaloff Fletcher, S. E., Pacala, S., and Rodgers, K.: Trends and regional distributions of land and ocean carbon sinks, Biogeosciences, 7, 2351-2367, doi:10.5194/bg-7-2351-2010, 2010.

Schuster, U. and Watson, A. J.: A variable and decreasing sink for atmospheric $\mathrm{CO}_{2}$ in the North Atlantic, J. Geophys. Res. Oc. (1978-2012), 112, C11006, doi:10.1029/2006JC003941, 2007.

Stocker, B. D., Strassmann, K., and Joos, F.: Sensitivity of Holocene atmospheric $\mathrm{CO}_{2}$ and the modern carbon budget to early human land use: analyses with a process-based model, Biogeosciences, 8, 69-88, doi:10.5194/bg-8-69-2011, 2011.

Takahashi, T., Sutherland, S. C., and Kozyr, A.: Global Ocean Surface Water Partial Pressure of $\mathrm{CO}_{2}$ Database: Measurements Performed During 1957-2013 (Version 2013), Oak Ridge National Laboratory, US Department of Energy, Oak Ridge, Tennessee, ORNL/CDIAC-160, NDP-088(V2012), Carbon Dioxide Information Analysis Center, 2014.

Thoning, K. W., Tans, P. P., and Komhyr, W. D.: Atmospheric carbon dioxide at Mauna Loa Observatory: 2. Analysis of the NOAA GMCC data, 1974-1985, J. Geophys. Res. Atmos. (1984-2012), 94, 8549-8565, 1989.

View-CO2, G.: Cooperative Global Atmospheric Data Integration Project, updated annually, Multi-laboratory compilation of synchronized and gap-filled atmospheric carbon dioxide records for the period 1979-2012, 2013 Edn., Compiled by NOAA Global Monitoring Division: Boulder, Colorado, USA, 2013.

Wanninkhof, R., Park, G.-H., Takahashi, T., Sweeney, C., Feely, R., Nojiri, Y., Gruber, N., Doney, S. C., McKinley, G. A., Lenton, A., Le Quéré, C., Heinze, C., Schwinger, J., Graven, H., and 
Khatiwala, S.: Global ocean carbon uptake: magnitude, variability and trends, Biogeosciences, 10, 1983-2000, doi:10.5194/bg10-1983-2013, 2013.

Yang, X., Richardson, T. K., and Jain, A. K.: Contributions of secondary forest and nitrogen dynamics to terrestrial carbon uptake, Biogeosciences, 7, 3041-3050, doi:10.5194/bg-7-30412010, 2010.
Zhao, M. and Running, S. W.: Drought-induced reduction in global terrestrial net primary production from 2000 through 2009, Science, 329, 940-943, 2010. 